\title{
Article \\ Evaluation of Numerical Simulation Approaches for Simulating Train-Track Interactions and Predicting Rail Damage in Railway Switches and Crossings (S\&Cs)
}

\author{
Nikhil Pillai ${ }^{1, *}$, Jou-Yi Shih ${ }^{1,2}$ a and Clive Roberts ${ }^{1}$ \\ 1 Birmingham Centre for Railway Research and Education, University of Birmingham, \\ Birmingham B15 2TT, UK; J.Shih@bham.ac.uk (J.-Y.S.); C.ROBERTS.20@bham.ac.uk (C.R.) \\ 2 ZynaMic Engineering AB, 12070 Stockholm, Sweden \\ * Correspondence: NRP817@bham.ac.uk
}

Citation: Pillai, N.; Shih, J.-Y.; Roberts, C. Evaluation of Numerical Simulation Approaches for Simulating Train-Track Interactions and Predicting Rail Damage in Railway Switches and Crossings (S\&Cs). Infrastructures 2021, 6, 63. https://doi.org/10.3390/

infrastructures 6050063

Academic Editor: Davide Lo Presti

Received: 6 March 2021

Accepted: 20 April 2021

Published: 22 April 2021

Publisher's Note: MDPI stays neutral with regard to jurisdictional claims in published maps and institutional affiliations.

Copyright: (C) 2021 by the authors. Licensee MDPI, Basel, Switzerland. This article is an open access article distributed under the terms and conditions of the Creative Commons Attribution (CC BY) license (https:// creativecommons.org/licenses/by/ $4.0 /)$.

\begin{abstract}
Switch and crossing (S\&C) faults are a major cause of track-related delays and account for a significant proportion of maintenance and renewal budgets for railway infrastructure managers around the world. Although various modelling approaches have been proposed in the literature for the simulation of vehicle-track dynamic interaction, wheel-rail contact and damage prediction, there is a lack of evaluation for combining these approaches to effectively predict the failure mechanism. An evaluation of $S \& C$ modelling approaches has therefore been performed in this article to justify their selection for the research interests of predicting the most dominant failure mechanisms of wear, rolling contact fatigue (RCF) and plastic deformation in $\mathrm{S} \& \mathrm{C}$ rails by recognising the factors that influence the accuracy and efficiency of the proposed modelling approaches. A detailed discussion of the important modelling aspects has been carried out by considering the effectiveness of each individual approach and the combination of different approaches, along with a suggestion of appropriate modelling approaches for predicting the dominant failure mechanisms.
\end{abstract}

Keywords: railway switches and crossings (S\&Cs); numerical simulation; digital twin; wear; rolling contact fatigue (RCF); plastic deformation; multi-body simulation; finite element analysis

\section{Introduction}

Switches and crossings (S\&Cs) account for a high proportion of expenditure from maintenance and renewal budgets for rail infrastructure managers around the world. Despite making up a very small portion of the total track mileage in the UK, S\&Cs have traditionally contributed disproportionately to time delays as well as the maintenance and renewal budgets for Network Rail. Along with the financial aspect, two major incidents in the UK due to S\&C failure, at Potters Bar and Grayrigg in the 2000s, have put a focus on rail safety and have incentivised research into the field of predicting $S \& C$ degradation.

A major reason for this disproportionate failure of $S \& C$ s lies in their mechanical design. In railway switches, the wheel first passes over the stock rail before it is transferred over to the switch rail. In this region of transition from the stock to switch rail, rails are subjected to higher lateral forces and uneven load distribution due to variation of geometry, as well as contact with the wheel flange in the diverging route. For a common crossing, the wheel first passes over the wing rail before it transitions over to the crossing nose through a gap or discontinuity between the rails, resulting in a high-amplitude impact load on contact near the crossing nose. Therefore, compared to plain line rail, more discontinuous sections in S\&Cs lead to significant lateral and normal impact forces on S\&C rails as trains pass, leading to more frequent structural failures.

Numerical simulation approaches, which have been widely used for efficient damage prediction in S\&Cs, have been adopted without a justification for the selection process for several instances in the literature. Therefore, the main contribution of this article is the 
evaluation of different numerical simulation approaches by identifying and discussing the most important criteria influencing the selection of an appropriate approach for damage prediction, aided by a thorough review of the modelling examples present in the literature. From the existing literature, the $S \& C$ faults with the most safety and cost attribution concerns have been traced down to three main failure mechanisms. For a given failure mechanism, the most appropriate modelling approaches for damage prediction, wheel-rail contact simulation and dynamic vehicle-track interaction have been suggested for rails in S\&C panels.

The different types of deterioration/failure mechanisms seen in rails can be classified into two distinct categories. Category 1 includes local defects which are a result of mechanisms in the proximity of the wheel-rail contact interface and Category 2 includes failure mechanisms occurring remote from the contact patch, which are caused by more global system conditions such as track quality, manufacturing defects and abnormal/impact loading [1]. The main Category 1 failure mechanisms which cause a variety of defects on $S \& C$ rails include wear, rolling contact fatigue (RCF) and plastic deformation.

During the contact between wheel and rail surfaces, bonding occurs between surface asperities at discrete points or junctions. These junctions break off when the surfaces move relative to each other, and the tip is plucked off the softer surface and adheres to the harder surface, loosening the next layer of the surface tip, subsequently paving the way to wear debris [2]. Wear in switch panel rails is mainly caused when high creepage or differential velocity [3], as well as high tangential forces, is experienced by the switch and stock rails, especially on the diverging route. High lateral wear in rails could potentially result in critical widening of the rail gauge, leading to reduced structural integrity and thus fracture of rails in highly vulnerable locations such as the switch tip [4].

Repeated vehicle loading and passage over $\mathrm{S} \& \mathrm{C}$ rails, especially at locations with discontinuities, and high impact of the wheel would lead to RCF, which typically manifests itself in the form of the removal of material from the rail surface or cracks in the subsurface. The three stages through which RCF damage takes place in S\&Cs are crack initiation, crack propagation and final fracture or collapse of the structure. A reason for the initiation of surface RCF cracks, which can be identified as the removal of material from the rail surface, is ratcheting through the accumulation of plastic deformation on the rail head, caused by high contact stresses and forces influenced by steering and traction [5]. Subsurfaceinitiated RCF occurs underneath the running rail surface, typically magnified at the rail gauge corner, and is most likely to occur under operational conditions with high normal wheel-rail contact forces and smaller contact patches along with the combined effect of material defects [5].

Plastic deformation or permanent damage of $S \& C$ rail material is induced when high loading of the rails results in the material experiencing stresses beyond its elastic limit, resulting in residual stresses changing the internal material microstructure. The magnitude of deformation is influenced by loading as well as material condition, with different rates of deformation taking place in the elastic shakedown, plastic shakedown and ratcheting regimes [3]. Following the first cycle of the permanent deformation of the internal structure, the material enters the elastic shakedown regime where the presence of very low residual stresses allows the same load to be carried elastically without resulting in permanent plastic deformation. When the elastic shakedown limit is exceeded, the material enters cyclic plasticity or the plastic shakedown regime. In this regime, the material experiences microstructural deformation at every loading cycle. Once the plastic shakedown limit is exceeded, each loading cycle results in high permanent deformation and plastic strains, which would finally culminate in the collapse of the structure [3].

S\&C rail faults whose main failure mechanism is RCF include spalling, shelling, cracks in the rail, head checks and squats. Spalling is identifiable by cavities and subsequent fracture on the railhead and is initiated through recurring extrusion from high wheel-rail contact stresses, resulting in the initiation and propagation of micro-cracks [6]. Shelling is identifiable as material peeling off the rail surface and initiates by a small crack on the rail 
surface, reducing the structural integrity on subsequent multiplication and merging [6]. Head checks are observed in the form of parallel cracks on the rail gauge corner and initiate from RCF on the surface rail [7]. Squats are a result of the longitudinal displacement of railhead cracks, followed by propagation into the subsurface rail and subsequent lateral spread [8].

Either the individual or combined effects of the failure mechanisms of plastic deformation and rail wear lead to rail defects such as lipping, wheel burns and rail corrugations. Lipping, which is identifiable by material resettlement in the lower rail gauge corner, is the result of plastic ratcheting [9]. Wheel burns, identifiable as erosion of the railhead material, are caused by plastic deformation due to wheel slip and high thermal stresses [4]. Corrugation, which is identifiable as irregularities and running bands on the railhead, is initiated when a 'wavelength fixing mechanism' is excited during the dynamic vehicle/track interaction by the nominal rail profile with roughness at different wavelengths [10,11]. Subsequent rail wear and plastic deformation modify the rail profile and trigger the wavelength fixing mechanism, further aggravating the corrugation [11]. Progressive transverse cracking, a form of lateral internal crack in the railhead subsurface, is caused by a combination of material defects and heavy gauge corner shelling [4].

An important Category 2 fault that occurs away from the wheel-rail interface is rail fracture, whose causal failure mechanism is RCF and plastic deformation. Fracture in the rail foot, which resulted in the highest failure cost for crossings in the UK according to Network Rail databases for 2009-2012 [1], is the result of wheel-rail contact forces causing the bending stresses to focus on concentrated and weak areas of the rail foot. Dynamic loading over the rail is typically magnified by rail irregularities generated at the crossing and results in rail foot fracture when such repeated high loading exceeds the ultimate tensile strength of the material. It has been foreseen that the trend in increased loading and mechanical handling of the rails would promote an increase in rail foot cracks [5].

Thus, among S\&C rail faults influenced by wheel-rail contact, most are reliant on wear, RCF and plastic deformation for their occurrence, as summarised in Table 1. Moreover, it has been concluded that the contribution of $S \& C$ rail wear and fracture to the financial expenditure borne by rail infrastructure managers is considerable [1]. The present work aims to identify the most effective methods able to capture specific $S \& C$ faults by assessing existing modelling approaches to predicting $S \& C$ rail failure mechanisms. The methodology adopted in this research involves the identification of dominant $S \& C$ rail faults and recognition of the common failure mechanisms resulting in these faults. Three failure mechanisms, wear, plastic deformation and RCF, are considered since they are the most important causes of common S\&C faults, as justified in Table 1. A review of the approaches to the numerical simulation of dynamic vehicle-track interaction, wheel-rail contact and damage prediction has been conducted from the vast amount of literature on the topic, and the key variables to be obtained from each model for the prediction of different failure mechanisms have been identified. Additionally, the vital features of the numerical simulation approaches which influence their accuracy and efficiency to predict a given failure mechanism have been recognised. In the concluding sections, the appropriateness of the simulation approaches concerning these features has been evaluated for predicting the different failure mechanisms.

Table 1. Relating faults to primary damage mechanism.

\begin{tabular}{cc}
\hline Fault in S\&C & Damage Mechanism (Wear/RCF/Plastic Deformation) \\
\hline Spalling & RCF [12]. \\
\hline Lipping & Plastic deformation [9,13]. \\
\hline Shelling & Subsurface RCF [4,14], plastic deformation due to cyclic loading [14]. \\
\hline Cracks in rail & RCF [14]. \\
\hline
\end{tabular}


Table 1. Cont.

\begin{tabular}{cc}
\hline Fault in S\&C & Damage Mechanism (Wear/RCF/Plastic Deformation) \\
\hline Head checks & Surface-initiated RCF [7]. \\
\hline Squats & Surface-initiated RCF [8]. \\
\hline Progressive transverse cracking & Shelling in gauge corner [4]. \\
\hline Wheel burns & Plastic deformation due to wheel slip and rail head wear [4]. \\
\hline Corrugations & Wear because of longitudinal wheel slip [15], cyclic plastic deformation [15], wear and \\
plastic deformation [4,10,11].
\end{tabular}

\section{Numerical Simulation Approaches to Simulating the Interaction between Railway Vehicles and S\&Cs}

Different numerical simulation approaches to modelling the dynamic interaction between railway vehicles and S\&Cs are introduced below, followed by a summary of their advantages, limitations and associated research interest in the literature at the end of each section. A detailed discussion around the reasons for those advantages and limitations is carried out in Section 5.

\subsection{Multi-Body System (MBS) Simulation}

Vehicle/track dynamic interaction is determined by considering rigid elements for the vehicle and track in an MBS. S\&Cs are modelled in an MBS with rigid elements (mass/spring/damper), where every wheelset is accompanied by one moving rigid track system [12], also known as a co-running track. Track flexibility is considered by varying the properties of the spring-dashpot element assigned in vertical and lateral directions, as shown in Figure 1. In the single-layer track system shown in Figure 1, the railpad and substructure dynamic properties are combined and the complete track system is coupled with the vehicle model [16]. A major limitation of the single-layer MBS track model is its ability to capture low-frequency track dynamics, which is more suited to studying vehicle ride dynamics [17].

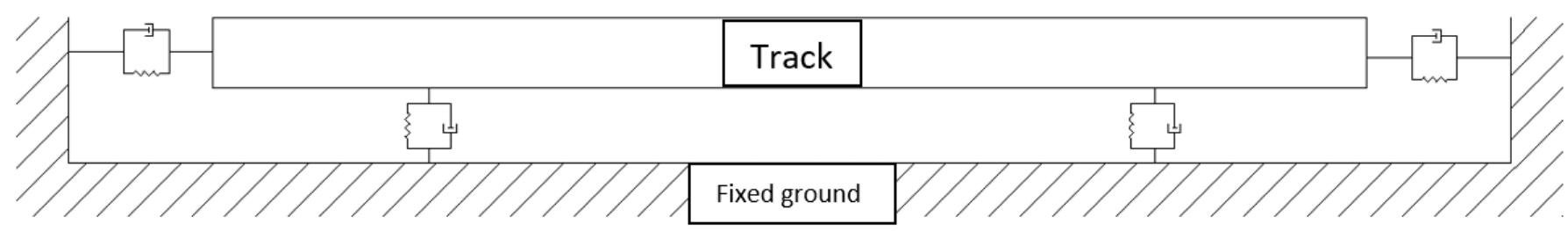

Figure 1. Co-running track model with track flexibility (adapted from [16]).

Different numbers of track layers may be considered to improve track flexibility and consider high-frequency dynamics. In a multi-layer track system, multiple rigid masses are used to represent the degrees of freedom (DOF) for the rails, sleeper and potentially ballast. As shown in Figure 2, multiple masses and DOF were considered in a three-layer track system [18]. Although the inclusion of multiple DOF increases processing time, it allows for more flexibility and consideration of higher frequencies, reflected in the accuracy of model outputs.

MBS simulations are best suited for solutions that demand consideration of vehicle dynamics, as well as quick simulations such as those implementing parametric studies in terms of wheel and track geometry changes, and speed and friction coefficient variation without the study of detailed subsurface stress distributions. The advantages, limitations and associated research interest for the MBS modelling of S\&Cs from the reviewed literature is summarised in Table 2. 


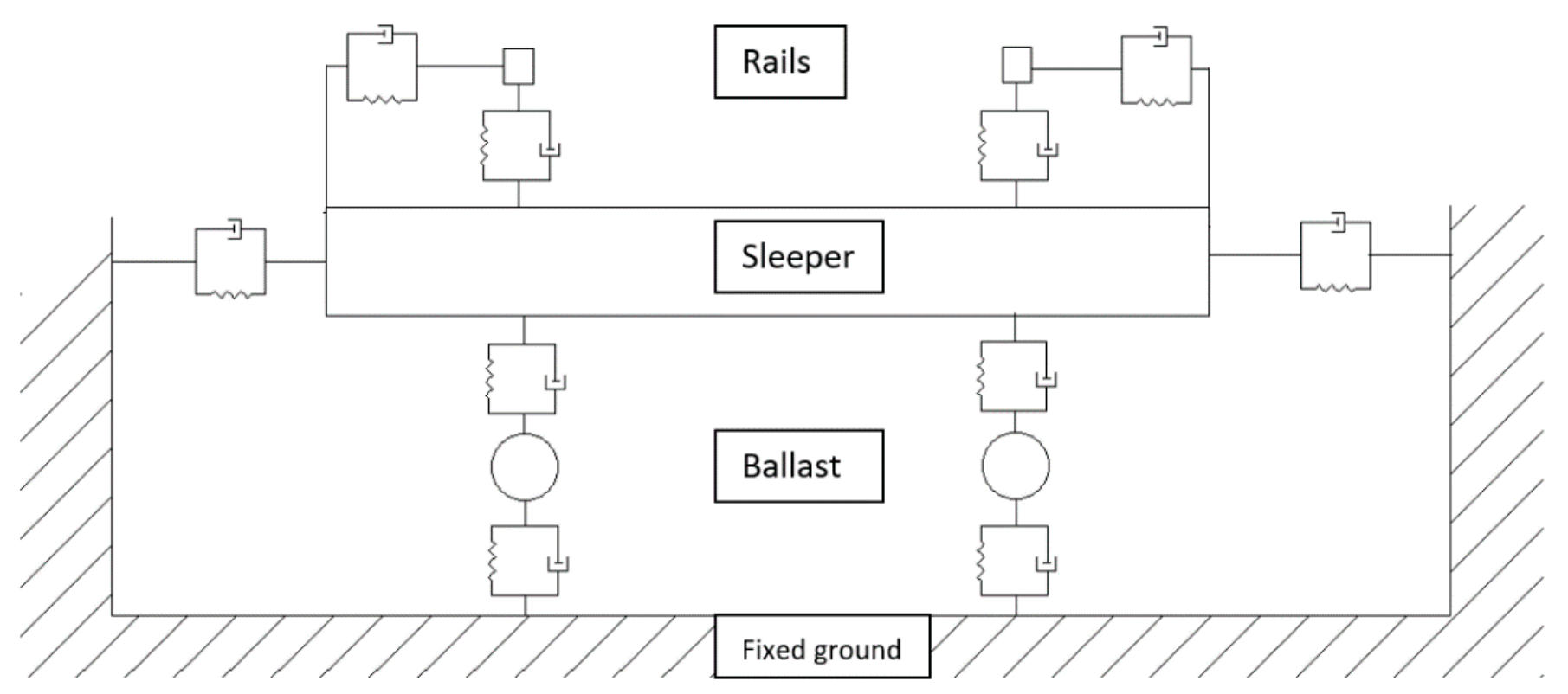

Figure 2. Co-running track with multiple DOF (adapted from [18]).

Table 2. Summary of pure MBS numerical approach.

\begin{tabular}{|c|c|c|}
\hline Advantages & Limitations & \multirow{10}{*}{$\begin{array}{c}\text { Research Interest } \\
\text { Switch wear prediction [12,19-24]. } \\
\text { Crossing wear prediction }[18,21,22] . \\
\text { Switch surface RCF } \\
\text { prediction }[12,20,22,25,26] . \\
\text { Crossing surface RCF prediction [22]. } \\
\text { Vehicle/turnout dynamics [27-33]. } \\
\text { New switch concept [34]. } \\
\text { Vehicle performance [35]. } \\
\text { Wheel damage [36,37]. } \\
\text { S\&C geometry optimisation [38-41]. } \\
\text { Field calibration [42]. } \\
\text { Contact model validation [27]. } \\
\text { Flexible track model validation [17,28,43] } \\
\text { FE model validation [44-46]. }\end{array}$} \\
\hline \multicolumn{2}{|c|}{ Single-layer co-running track } & \\
\hline High efficiency [25]. & Only captures low-frequency & \\
\hline Detailed consideration of vehicle dynamics [25]. & content [17]. & \\
\hline Acceptable results for low-frequency & Less representative substructure & \\
\hline applications $[17,25]$. & mechanical behaviour [9]. & \\
\hline Representative surface damage predictions & Poor consideration of $S \& C$ rail & \\
\hline based on the contact model [12]. & cross-section variation [12]. & \\
\hline \multicolumn{2}{|c|}{ Multi-layer co-running track } & \\
\hline $\begin{array}{c}\text { Independent consideration of S\&C component } \\
\text { dynamics [18,42]. } \\
\text { Captures higher-frequency content than } \\
\text { single-layer track [18]. }\end{array}$ & $\begin{array}{l}\text { Accurate results limited to } \\
\text { frequencies up to } 200 \mathrm{~Hz} \text { [21]. } \\
\text { Reduced efficiency [18]. }\end{array}$ & \\
\hline
\end{tabular}

\subsection{Finite Element (FE) Simulation Approach}

High-frequency dynamics as well as various non-linearities during the vehicle/track interaction are regarded in FE analysis (FEA) using beam/solid element models. By considering rail profile machining tools and milling thickness [39], the 3D geometry of S\&C rails can be drawn and imported into FE as solid elements. For solutions demanding wheel/rail contact patch information, a solid model of the unsprung wheel or a complete wheelset is incorporated into the FE model. The substructure is either modelled using solid elements or simplified to rigid elements.

The main approaches to S\&C numerical simulation using FEA have either been through the consideration of a single wheel and track side (half-track model), a complete wheelset and full track, or through the application of concentrated loads on the rails of a detailed solid element turnout model with full geometry. The implication of these modelling approaches for considering vehicle dynamics is discussed in Section 5.1.

The poor efficiency of FE models demands model simplification for cyclic analyses. Some models simplify the geometry of the rail in order to improve the efficiency for cyclic simulations [47,48], and some make a plane strain assumption for cyclic simulations at certain rail cross-sections $[25,49]$. Others obtain accurate results with a very detailed 
FE model for a single run and then substitute those outputs to empirical models for cyclic estimations [14]. The dynamic response can be obtained in a coarsely meshed global FE model of a larger region, whose results may be used as boundary conditions in a subsequently developed finely meshed local sub-model for predicting damage of a smaller geometry [50-52]. The importance of considering the behaviour of non-linear plastic material, which is possible through FE models, is discussed in Section 5.3. Table 3 summarises the advantages, limitations and research interests associated with different types of FE turnout models.

Table 3. Summary of FE numerical approach for S\&Cs.

\begin{tabular}{|c|c|c|}
\hline Advantages & Limitations & Research Interest \\
\hline \multicolumn{3}{|c|}{ Solid element FE half-track model } \\
\hline $\begin{array}{l}\text { Reduced number of elements, higher efficiency. } \\
\text { Non-linear elastic-plastic material behaviour for } \\
\text { better prediction of contact stress/damage [45]. } \\
\text { Implementation of cyclic degradation [48]. } \\
\text { Consideration of a solid sleeper [53]. }\end{array}$ & $\begin{array}{c}\text { Poor efficiency. } \\
\text { Simplified vehicle dynamics [45]. } \\
\text { Constant yaw angle used for the } \\
\text { wheel in the diverging route [45]. } \\
\text { Underestimation of slip, lateral } \\
\text { and longitudinal tangential } \\
\text { contact forces [54]. } \\
\text { Assumptions in substructure } \\
\text { simplification/property } \\
\text { assignment [45]. }\end{array}$ & $\begin{array}{c}\text { Crossing wear }[45,46,53,55] . \\
\text { Crossing RCF [46-48]. } \\
\text { Crossing plastic } \\
\text { deformation }[45,48,53-57] . \\
\text { Wheel/crossing impact } \\
\text { behaviour [56-61]. } \\
\text { Incorporation of RCF damage in rail [62]. }\end{array}$ \\
\hline
\end{tabular}

Solid element FE model for full track, including the opposite stock rail

\footnotetext{
Non-linear elastic-plastic material behaviour for better contact stress/damage prediction [14]. Implementation of cyclic degradation [63]. Representative wheelset displacement [14]. Sleeper and substructure material behaviour and vehicle dynamics $[14,63,64]$.

Sleeper and substructure stress distribution outputs $[14,63,64]$.
}

\section{Direct application of axle load in absence of wheel geometry}

Complete turnout substructure modelled [69]. Stress distributions in all turnout components [69].

Input loads for a complete train [69].
Poor efficiency [69].

Wheel/rail contact ignored [69].

Point loading rather than through a contact patch [69].
Crossing wear [65-67]. Crossing surface RCF [65]. Crossing fatigue life [14,51]. Switch component plastic deformation in special case run-through [68]. Crossing plastic deformation [65-67]. Bearer and ballast mechanical behaviour [69].

Wheel/crossing contact behaviour [64]. Wheel/switch contact behaviour [44].

Dynamic behaviour of all S\&C components [70].

\subsection{Combined MBS and FE Modelling Approaches}

A holistic consideration of vehicle dynamics, material behaviour, rail subsurface and substructure mechanical behaviour can be implemented through a combined MBS-FE simulation approach $[16,25]$.

MBS and FE approaches can be used in conjunction, either by substitution or by co-simulation. In the former approach, the results from the first numerical tool are saved and substituted into the second after the passage of a vehicle over the complete length of track.

As defined by Smith [71], co-simulation can be carried out in parallel, sequentially or iteratively. Parallel co-simulation involves running two numerical tools simultaneously and exchanging information to update the respective solutions at the next coupling target time, with the benefit of efficiency and the limitation of instability. In sequential co-simulation, analysis in the first numerical tool leads the second and information will be exchanged at defined coupling steps whilst the same run or passage of the vehicle over the track takes place. Similar to the sequential scheme, co-simulation through iterative coupling involves the first tool leading the second and information being exchanged at defined coupling steps 
but more elaborately, with the execution of multiple exchanges at each coupling step until the termination criteria are met [71].

A number of combined simulation approaches based on substitution have been adopted for S\&Cs in the literature. MBS model outputs of relevant wheel-S\&C contact loads, positions and radii of curvature have been used to generate a 3D solid element FE model with simplified geometry as a substitute for an empirical wheel-rail contact model for more accurate contact patch outputs under elastic-plastic material conditions [25]. An MBS model, a wheel/rail contact meta-model with the ability to consider elastic-plastic hardening material behaviour, and a 2D plane strain FE model have been combined to predict plastic deformation [18]. Outputs for contact positions and forces from the MBS model were used in the wheel-rail contact meta-model to obtain contact patch sizes/pressures, which were inputs to the 2D plane strain model to obtain subsurface rail stress distribution for predicting plastic deformation [18]. The compatibility between MBS and FE models in terms of contact point locations, bedding properties and the stabilisation of results must be ensured.

MBS models can be coupled with reduced-order models for improved computational efficiency and consideration of higher frequencies. Flexible components can be brought into MBS by translating the FE component into a number of representative eigenfrequencies and mode shapes that accurately represent its behaviour under dynamic conditions [72] Modal reduction methods involve reducing the flexible body problem by describing it in terms of the sums of its mode shapes, where outputs in terms of 'node locations and connectivity, nodal mass and inertia, mode shapes and generalised mass and stiffness matrices for the mode shapes' are used to describe the flexible body [72]. Flexible track models with the ability to capture higher-frequency characteristics have been implemented by importing FEA models into MBS packages by using modal reduction methods. Flexible track models employing beam elements, although less efficient than MBS models, are able to consider the high-frequency impact and longitudinal variation of S\&C track properties including track geometry. However, for applications that require detailed subsurface stress/strain distribution outputs, the modal reduction in solid element FE models is more desirable.

Unlike combined simulation approaches where solutions are obtained from different solver packages, the simulation is carried out by importing an FE model through modal reduction for interaction with a multiple-DOF rigid vehicle model in a single solver. Thus, the substructure properties of the flexible track are imported into the simulation package, eliminating the need for calibration between multiple models. Following the pre-processing of wheel-rail contact locations using 2D cross-sections, dynamic vehicle/track interaction is carried out between the rigid vehicle and flexible components of the track, necessitating a good agreement of the rail profiles used in the pre-processor and FE flexible track geometry [73]. The solution and post-processing of results from flexible track models are limited by computational efficiency and would require the choice of specific nodes of interest. Another limitation of this approach is the application of concentrated forces to contact points, instead of applying distributed loading/pressure through a 3D contact patch. Moreover, analyses with flexible track models are limited to a linear system.

The importance of substructure property calibration among models for use in cosimulation is explained in Section 5.2. A summary of the advantages and limitations, as well as examples in the literature of modelling through combined approaches, is shown in Table 4. 
Table 4. Summary of combined independent modelling approach for S\&Cs.

\begin{tabular}{|c|c|c|}
\hline Advantages & Disadvantages & Research Interest \\
\hline \multicolumn{3}{|c|}{ Combined MBS-FE Simulation } \\
\hline \multicolumn{2}{|c|}{ MBS/solid element FE } & Switch wear $[20,25]$. \\
\hline $\begin{array}{c}\text { Representative wheelset displacements and } \\
\text { vehicle dynamics }[16,25] \text {. } \\
\text { Efficient analysis with simplified } \\
\text { geometry }[18,25] \text {. } \\
\text { Track non-linearity considered [16]. } \\
\text { Cyclic material degradation considered [18,25]. } \\
\text { Cyclic rail profile updated [25]. }\end{array}$ & $\begin{array}{l}\text { Less efficient than pure } \\
\text { MBS models [25]. } \\
\text { Effects of substructure } \\
\text { ignored during FE } \\
\text { wheel/rail contact }[16,25] \text {. }\end{array}$ & $\begin{array}{c}\text { Switch RCF [16,20]. } \\
\text { Switch plastic deformation }[25,74] . \\
\text { Crossing wear }[18,75,76] . \\
\text { Crossing RCF }[16] . \\
\text { Crossing deformation }[18,75] . \\
\text { Substructure dynamics/S\&C settlement }[77-83] . \\
\text { Vehicle/turnout dynamics }[16,29,84-87] \text {. } \\
\text { Sensor location determination for S\&C condition }\end{array}$ \\
\hline \multicolumn{2}{|c|}{ MBS/beam element FE } & monitoring [88]. \\
\hline $\begin{array}{l}\text { High efficiency }[77,85] . \\
\text { Substructure dynamics considered [77]. } \\
\text { Very high efficiency of 2D models [79]. }\end{array}$ & $\begin{array}{l}\text { Subsurface outputs cannot } \\
\text { be analysed [77]. } \\
\text { Many calibrated inputs } \\
\text { needed for 2D FEA [79]. }\end{array}$ & $\begin{array}{c}\text { Wheel-rail contact model comparison [89]. } \\
\text { Crossing model validation [90]. } \\
\text { Wheel behaviour [91]. } \\
\text { Switch movement force [92]. }\end{array}$ \\
\hline \multicolumn{3}{|c|}{ Combined MBS-FE simulation with modal reduction } \\
\hline $\begin{array}{l}\text { More efficient than FE [43]. } \\
\text { Reducing number of modes / DOF improves } \\
\text { efficiency [17]. } \\
\text { Captures higher-frequency content [43]. } \\
\text { Substructure dynamics considered [43]. }\end{array}$ & $\begin{array}{l}\text { Poorer efficiency than } \\
\text { MBS [43]. } \\
\text { Linear track model [93]. }\end{array}$ & $\begin{array}{c}\text { S\&C wear [94,95]. } \\
\text { S\&C surface RCF [94]. } \\
\text { Vehicle/crossing dynamics [96]. } \\
\text { Vehicle/turnout dynamics }[17,28,43,72,96,97] . \\
\text { Substructure dynamics }[98] . \\
\text { Impact loads on crossing }[93,98,99] . \\
\text { Wheel derailment over switch }[100,101] .\end{array}$ \\
\hline
\end{tabular}

\section{Wheel/Rail Contact Modelling}

Approaches for solving wheel/rail contact problems are different for MBS and FE models. In MBS modelling, the contact locations are usually retabulated based on wheel/rail movements to increase the efficiency. Contact forces are then calculated based on the material stiffness and deformation. The calculation for the contact pressure and contact patch in MBS can be solved either analytically or numerically based on different contact models and sometimes empirical equations may be used to increase the efficiency for solving contact problems numerically. However, a common limitation has been found for all wheel-rail contact models used in the literature for predicting surface damage in S\&Cs. The first step of the wheel-rail contact modelling involves the calculation of contact forces based on the non-linear material stiffness and deformation whilst considering high-frequency vehicle and track dynamics. However, in the subsequent step where contact patch pressure and size are estimated, quasi-static conditions are assumed. Therefore, the value of the contact force is directly substituted into the wheel-rail contact model to determine the contact patch geometry and pressures whilst ignoring the consequence of the frequency at which it has been obtained. In FE modelling, the wheel-rail contact conditions are not predetermined and calculation of the contact geometry, forces and pressures is carried out at every time step by defining a normal and tangential contact algorithm. Normal and tangential wheel/rail contact models used for S\&C modelling in the literature are elaborated in Sections 3.1 and 3.2, respectively.

\subsection{Normal Contact Modelling}

For normal wheel/rail contact modelling in S\&Cs, various Hertzian and non-Hertzian contact approaches have been implemented.

From the review, the most widely used contact model in MBS is the one by Hertz [102], which assumes an elliptical point contact between the wheel and rail and is accurate when subject to the criteria mentioned in Table 5, which are often not met in the transition regions of S\&Cs. Recently, elastic-plastic hardening material behaviour was implemented in a 
Hertzian-based meta-model [49] to improve the contact model's consideration of cyclic material behaviour, but further work is needed to validate the results.

An improvement over the Hertzian method has been achieved with the multi-Hertzian approach, by improving the contact patch shape through the division of the contact patch into multiple ellipses and considering a penetration function based on the wheel/rail shape geometry [96]. However, this model is still subject to other Hertzian assumptions [96].

Another improvement over the Hertzian method, the semi-Hertzian approach, improves accuracy by considering wheel/rail virtual penetration. The semi-Hertzian approach developed by Piotrowski and Kik [103] is limited by assumptions made to calculate the depth of penetration; it was improved by Ayasse and Chollet [104] by introducing curvature correction measures and the discretisation of the contact patch into strips. The semi-Hertzian approach ANALYN achieves improved accuracy by considering a parameter named approximate surface deformation (ASD) [105]. In summary, the semi-Hertzian method improves the estimation of the contact patch by considering the penetration of the wheel/rail contact, but it is still limited to the pure elastic contact assumption.

Table 5. Normal contact modelling approaches.

\begin{tabular}{ccc}
\hline Advantages & Limitations/Assumptions & Reference Examples \\
\hline & Hertzian [102] & Switch \\
& & Wear [12,20,25]. \\
RCF [12,20,25]. \\
High efficiency and accuracy & Assumes small strains, elastic half spaces, no & Plastic deformation [25,74]. \\
when assumptions are met [9]. & Crossing \\
Introduction of a meta-model & friction/tangential contact [9]. & Wear [18,75,76]. \\
with elastic-plastic hardening & Poor for conformal, asymmetric multi-point & Plastic deformation $[18,75,76]$. \\
and non-linear cyclic material & contact [9]. & Complete turnout \\
behaviour [18,49]. & & Wear [21,22,95]. \\
& & RCF [22].
\end{tabular}

\section{Multi-Hertzian [96]}

$\begin{array}{ccc}\text { Better contact patch } & \text { Hertzian assumptions remain valid [9]. } & \text { Complete turnout } \\ \text { geometry [9]. } & \text { Elastic material behaviour [9]. } & \text { Vehicle/turnout dynamics [96,97]. } \\ \text { Good efficiency [9]. } & \end{array}$

Semi-Hertzian $[103,105]$

\begin{tabular}{|c|c|c|}
\hline $\begin{array}{l}\text { Improved accuracy of contact } \\
\text { geometry through contact patch } \\
\text { discretisation } \\
\text { and penetration [20]. }\end{array}$ & $\begin{array}{c}\text { Poorer efficiency than Hertzian/ } \\
\text { multi-Hertzian [107]. } \\
\text { Penetration value based on assumptions [20]. } \\
\text { Elastic material [107]. } \\
\text { Accuracy limited to symmetric contact patch [9]. }\end{array}$ & $\begin{array}{c}\text { Switch } \\
\text { Wear }[19,20,23] . \\
\operatorname{RCF}[20,26] .\end{array}$ \\
\hline \multicolumn{3}{|c|}{ Kalker's CONTACT [106] } \\
\hline \multicolumn{3}{|c|}{ CONTACT [106] } \\
\hline $\begin{array}{l}\text { Considers a variety of contact } \\
\text { patch shapes }[9,106] . \\
\text { Benchmark for other contact } \\
\text { models }[20] .\end{array}$ & $\begin{array}{l}\text { Poor efficiency }[9,20] \text {. } \\
\text { Pure elasticity }[9,106] \text {. }\end{array}$ & \multirow{3}{*}{$\begin{array}{c}\text { Switch } \\
\text { Wear [20]. } \\
\text { RCF [20]. } \\
\text { Vehicle/turnout dynamics/new contact } \\
\text { model [27]. } \\
\text { Complete turnout } \\
\text { Wear [94]. } \\
\text { RCF [94]. }\end{array}$} \\
\hline & WEAR [27] & \\
\hline $\begin{array}{l}\text { Accurate conformal contact } \\
\text { modelling [27]. } \\
\text { Developed for S\&C [27]. }\end{array}$ & Ignores influence of traction [27]. & \\
\hline
\end{tabular}


Table 5. Cont.

\begin{tabular}{ccc}
\hline Advantages & Limitations/Assumptions & Reference Examples \\
\hline & FE normal contact (direct/penalty/augmented Lagrange) [71] & \\
\hline Real-time solution & & Switch \\
whilst considering & Pear [20,25]. & RCF [25]. \\
deformation/dynamics [108]. & Poor efficiency [9]. & Crossing \\
Gives subsurface stress & Effect of vehicle dynamics on contact is generally & Plastic deformation $[20,25,68]$. \\
distributions [9]. & ignored/simplified in FE. & Wear [45,46,53,55,65-67]. \\
Potential to consider non-linear & RCF [14,46,47,51,65]. \\
material behaviour [14,25]. & & Plastic deformation $[45,48,53-57,65-67]$. \\
\hline
\end{tabular}

The CONTACT algorithm by Kalker [106] is not limited to specific contact geometry and is widely used as the benchmark for wheel/S\&C contact modelling. Kalker's CONTACT model was improved to give more accurate results for conformal contact in an algorithm named WEAR [27].

The normal contact problem is solved for FEA in real time by using the 'hard contact' algorithm, which is enforced in the absence of clearance between two surfaces and removed when a contact pressure of zero magnitude is reached, leading to the separation of surfaces [71]. For simulating hard contact, three constraint enforcement methods named the direct method, penalty method and augmented Lagrange method are presented [71]. Different types of material behaviour can also be considered in FE modelling, which improves the accuracy of normal contact simulation and gives more realistic contact patches and pressures [89]. Table 5 summarises the advantages, limitations and applications of normal contact models applied to S\&Cs.

\subsection{Tangential Contact Models}

An appropriate representation of stick/slip regions, sliding velocity and creep parameters to obtain representative results for surface damage prediction and to consider accurate load propagation to the rail subsurface needs the implementation of an appropriate tangential contact algorithm.

The tangential component of Kalker's CONTACT algorithm [106] is based on the strip theory by Haines and Ollerton [109] and considers the rolling contact frictional problem in detail for a variety of contact patch shapes. This approach is considered as the benchmark solution for wheel/rail contact [9]. However, limitations for S\&C contact have been reported in the literature, such as convergence issues for solving multiple contact problems in a continuous simulation [27] and poor efficiency.

Based on the simplified theory by Kalker [106], the efficient FASTSIM algorithm has been widely implemented for S\&Cs and is said to give accurate creep estimations under usual conditions. However, for certain contact patch geometries and parabolic traction bounds, poor results for shear stresses and creepage have been reported [110]. Assumptions and simplifications considered for this model are highlighted in Table 6.

Semi-Hertzian approaches by Piotrowski and Kik [103] implemented the FASTSIM algorithm for tangential contact, which was refined by Ayasse and Chollet [104] in the algorithm STRIPES, by improving the handling of spin creepage and flexibility coefficients. Sichani et al. [110] modified the FASTSIM algorithm by developing the 'FaStrip' algorithm, considering a wider range of contact ellipses and effects of large spin. This was carried out by using a single weighted average of flexibility coefficients [110], to associate the shear stresses with creepage in three dimensions [20].

An extension of Kalker's CONTACT rail algorithm, WEAR, was developed to obtain more accurate results in flange contact regions, by replacing the elastic half-space assumption with the quasi-quarter space assumption in the gauge corner and flange root, due to the absence of planar contact [27]. The influence number, which relates the displacement vector of one element to the unit contact stress of another element in a particular direction, 
is obtained using FE, unlike the analytical approach of CONTACT [27]. Although there is improved accuracy by better consideration of geometry-dependent spin and wheelset yaw angle, the implementation of the model for a complete turnout is challenging due to the poor efficiency of the approach [27]. Poor results in the presence of conformal contact, as well as the assumption of a constant value of spin creepage, are common limitations of CONTACT and FASTSIM, which are corrected by WEAR and STRIPES, respectively $[27,104]$.

The theory by Shen-Hedrick and Elkins [111] is a modification of a previous theory by Vermeulen and Johnson [112] to include Kalker's creepage coefficients to achieve similar results to FASTSIM and CONTACT. Efficiency is improved up to 100 and 200 times in comparison with FASTSIM and CONTACT, respectively [106]. However, the model has been shown to give poor results in regions with flange contact and is valid only for assumptions of small spin and unrestricted creepage [106].

Table 6. Tangential contact modelling approaches.

\begin{tabular}{|c|c|c|}
\hline Advantages & Limitations & Reference Examples \\
\hline \multicolumn{3}{|c|}{ Shen-Hedrick-Elkins theory [106] } \\
\hline $\begin{array}{c}\text { Excellent efficiency [106]. } \\
\text { Consideration of creepage [106]. }\end{array}$ & $\begin{array}{l}\text { Assumes small spin and unrestricted } \\
\text { creepage [106]. } \\
\text { Poor for rail flange/gauge corner contact [106]. }\end{array}$ & $\begin{array}{c}\text { Crossing } \\
\text { Substructure dynamics [80]. }\end{array}$ \\
\hline \multicolumn{3}{|c|}{ FASTSIM [106] } \\
\hline $\begin{array}{l}\text { Good efficiency [109]. } \\
\text { Highly used for S\&Cs [109]. }\end{array}$ & $\begin{array}{c}\text { Elliptical contact patch [109]. } \\
\text { Stresses/creepage assumed at } \\
\text { ellipse centre [109]. } \\
\text { Parabolic traction bound gives inaccurate shear } \\
\text { stress estimation [110]. }\end{array}$ & $\begin{array}{c}\text { Switch } \\
\text { Wear }[12,20,25] . \\
\text { RCF }[12,20,25] . \\
\text { Plastic deformation }[25,74] . \\
\text { Crossing } \\
\text { Wear }[18,75,76] . \\
\text { Plastic deformation }[18,75,76] . \\
\text { Complete turnout } \\
\text { Wear }[21,22,95] . \\
\text { RCF }[22] .\end{array}$ \\
\hline \multicolumn{3}{|c|}{ Modified FASTSIM-STRIPES [113] } \\
\hline $\begin{array}{l}\text { Improved consideration of spin } \\
\text { creepage }[20,27,104] .\end{array}$ & $\begin{array}{l}\text { Parabolic traction bound, } \\
\text { similar to FASTSIM [104]. }\end{array}$ & $\begin{array}{l}\text { Switch wear }[19,20,23] . \\
\text { Switch RCF [20]. }\end{array}$ \\
\hline \multicolumn{3}{|c|}{ Modified FASTSIM-FaStrip [110] } \\
\hline $\begin{array}{l}\text { Variety of contact ellipses } \\
\text { considered [110]. } \\
\text { Improved consideration of high } \\
\text { values of creepage [110]. } \\
\text { Improved shear stress estimation } \\
\text { with elliptic traction bound [110]. } \\
\text { Good efficiency [110]. }\end{array}$ & Further validation required [110]. & $\begin{array}{l}\text { Switch wear [20]. } \\
\text { Switch RCF }[20,26] \text {. }\end{array}$ \\
\hline \multicolumn{3}{|c|}{ Kalker's CONTACT model [106] } \\
\hline $\begin{array}{l}\text { Unrestricted contact } \\
\text { patch shape [9,109]. } \\
\text { Considers elastic deformation [109]. }\end{array}$ & $\begin{array}{c}\text { Poor efficiency }[9,20] \text {. } \\
\text { Elastic half-space assumption still } \\
\text { a limitation [9]. }\end{array}$ & $\begin{array}{c}\text { Switch } \\
\text { Wear [20]. }\end{array}$ \\
\hline \multicolumn{2}{|c|}{ Modified CONTACT-WEAR [27] } & $\begin{array}{l}\text { RCF [20]. } \\
\text { Vehicle/turnout dynamics/new contact }\end{array}$ \\
\hline $\begin{array}{l}\text { Accurate for conformal contact [27]. } \\
\text { Considers spin creepage change } \\
\text { within the contact patch [27]. } \\
\text { Accurate consideration of yawing in } \\
\text { contact point detection [27]. }\end{array}$ & Very poor efficiency [27]. & $\begin{array}{l}\text { model [27]. } \\
\text { Complete turnout } \\
\text { Wear [94]. } \\
\text { RCF [94]. }\end{array}$ \\
\hline
\end{tabular}


Table 6. Cont.

\begin{tabular}{|c|c|c|}
\hline Advantages & Limitations & Reference Examples \\
\hline \multicolumn{3}{|c|}{ Coulomb's friction law (FEA) [71] } \\
\hline $\begin{array}{l}\text { Also used in CONTACT, } \\
\text { representative for } \\
\text { rail applications [106]. } \\
\text { Non-linear elastic-plastic material } \\
\text { behaviour can be considered. }\end{array}$ & $\begin{array}{l}\text { Poor efficiency. } \\
\text { Imperfect dynamic relaxation and vibrations in } \\
\text { FEA (for quasi-static simulations) [108]. }\end{array}$ & $\begin{array}{c}\text { Switch } \\
\text { Plastic deformation [68]. } \\
\text { Crossing } \\
\text { Wear }[45,46,53,55,65-67] . \\
\text { RCF }[14,46,47,51,65] . \\
\text { Plastic deformation }[45,48,53-57,65-67] .\end{array}$ \\
\hline
\end{tabular}

In FEA, surfaces in contact can carry a maximum amount of shear stress in a phenomenon known as sticking, beyond which they undergo relative sliding. The critical shear stress for initiating sliding is defined by the Coulomb friction model, after which sliding takes into consideration the contact pressure magnitude. The calculation of the ratio of stick and slip, also known as the coefficient of friction, is carried out to determine the transition between the two conditions [71]. Real-time transient analysis, considering elastic-plastic behaviour, is enabled through an FE frictional model. Imperfect dynamic relaxations and high vibrations affect the results obtained from tangential contact analysis using transient FEA, which was concluded after the comparison of results of tangential components in the wheel/rail contact patch against Hertz and CONTACT models [108]. Table 6 summarises the advantages, limitations and applications of tangential contact models applied to S\&Cs.

\section{Damage Prediction Models}

Approaches to predicting the failure mechanisms of wear, RCF and plastic deformation are described below, along with a summary of the capability, limitations and required input parameters from dynamic interaction/contact analyses for each damage prediction approach.

\subsection{Wear Prediction Models}

The investigation of a relationship between the occurrence of cracks on rails and RCF damage simulation has been carried out to develop the whole-life rail model [114], which states that a measure of the energy expended within the contact patch, $\mathrm{T} \gamma$, can be used to define the intensity of rail wear and RCF [115]. From experimental tests on rail grade $\mathrm{R} 260$, it was determined that a $\mathrm{T} \gamma$ value of less than $15 \mathrm{~J} / \mathrm{m}$ would cause no rail damage, values between 15 and $75 \mathrm{~J} / \mathrm{m}$ would initiate RCF, those between 75 and $175 \mathrm{~J} / \mathrm{m}$ denote increasing wear whilst reducing RCF initiation risk and values greater than $175 \mathrm{~J} / \mathrm{m}$ denote severe wear in the absence of RCF, since excessive wear would eliminate surface cracks [115]. The T $\gamma$ value indicating wear/RCF damage is different for different rail steels, as proven by the observation of excessive wear for R350 HT rail steel only for T $\gamma$ values greater than $400 \mathrm{~J} / \mathrm{m}$ [116]. Since experiments to obtain these values were performed on different material grades of plain line rail, it is recommended that further validation tests for the model are performed for S\&C rails [9]. The wear number $\mathrm{T} \gamma$ can be obtained by the summation of the product of creep forces and creepage in longitudinal, transverse and spin directions [117].

Among the reviewed literature, the most popular S\&C rail wear prediction model is Archard's wear law, which is used to calculate the volume of worn-off material by dividing the product of frictional work and the empirical wear constant by the hardness of the two materials in contact $[45,118]$. The empirical wear constant, also known as the nondimensional wear coefficient, is a value based on the material hardness and contact pressure; there are examples in the literature available for different $S \& C$ materials. The absence of relative sliding distance/velocity between the surfaces would make the depth/volume of wear measured using this relationship zero, rendering this model suitable for predicting wear due to slip in the contact patch. It has been suggested that this approach is suited to predicting wear using the local method, where the contact patch is discretised into 
elements; if the global method, where wear is computed over the complete contact patch, is to be used, then the model is limited, since the effect of spin cannot be considered [119].

Specific frictional power and work are the relationship between variables such as contact pressure, sliding velocity and friction coefficient, which have been obtained from dynamic wheel/rail interaction in S\&C FE models [45]. Although these results have been shown to be proportional to those obtained from Archard's wear model, more specific validation studies through comparison against micro-models and field experiments has been suggested [45]. A summary of the modelling aspects of the most commonly used wear models for S\&Cs along with references to examples in the literature are provided in Table 7.

Table 7. Summary of different wear models used with S\&C numerical simulation.

\begin{tabular}{|c|c|c|c|}
\hline Capability & Input Parameters & Limitation & Examples \\
\hline \multicolumn{4}{|c|}{$\mathrm{T} \gamma$ wear number [117] } \\
\hline $\begin{array}{l}\text { Qualitative risk of wear on the } \\
\text { rail surface [117]. } \\
\text { Categorisation of locations on } \\
\text { railhead surface on the basis } \\
\text { of the risk of wear/RCF } \\
\text { occurrence [114]. }\end{array}$ & $\begin{array}{l}\text { Creep forces and creepage in } \\
\text { longitudinal, transverse and } \\
\text { spin directions [12]. }\end{array}$ & $\begin{array}{l}\text { Further validation is required } \\
\text { for S\&Cs [9]. }\end{array}$ & $\begin{array}{c}\text { Switch [24]. } \\
\text { Crossing [46]. } \\
\text { Complete turnout } \\
{[21,22,94,95] .}\end{array}$ \\
\hline \multicolumn{4}{|c|}{ Archard's wear law [118] } \\
\hline $\begin{array}{c}\text { Magnitude of wear depth or } \\
\text { volume [45]. }\end{array}$ & $\begin{array}{l}\text { Contact force/pressure, } \\
\text { sliding distance/velocity, } \\
\text { duration of contact and } \\
\text { material hardness }[12,65] \text {. }\end{array}$ & $\begin{array}{l}\text { Feasible only for small spin when } \\
\text { computing wear globally across } \\
\text { the contact patch [119]. }\end{array}$ & $\begin{array}{l}\text { Switch }[12,19,20,23,25] \text {. } \\
\text { Crossing }[18,53,65,66,75] \text {. }\end{array}$ \\
\hline \multicolumn{4}{|c|}{ Specific frictional work and power [45] } \\
\hline $\begin{array}{c}\text { Proportional to wear } \\
\text { depth [45]. } \\
\text { Input to Archard's wear law } \\
\text { to obtain wear depth [45]. }\end{array}$ & $\begin{array}{l}\text { Contact pressures, sliding } \\
\text { velocity and friction } \\
\text { coefficient [45]. }\end{array}$ & Further validation required [45]. & Crossing $[45,55,67]$. \\
\hline
\end{tabular}

There are also examples where $S \& C$ wear was included to study its impact on subsurface stress/strain outputs during vehicle-track interactions [16]. Damage prediction models could potentially be used to predict the propagation of wear in rail profiles measured in the field. More recently, statistical methods are being used to predict the remaining useful life using numerical simulation outputs of the magnitude of damage. For plain line rail, a meta-model implementing response surface methodology (RSM) has been used to predict the number of cycles to reach the critical wear depth by using simulation outputs from a single run of Archard's wear model [120]. The prediction was compared to the result obtained from cyclic numerical simulations and showed good agreement.

\subsection{RCF Prediction Models}

Approaches to predicting faults due to surface and subsurface RCF have been discussed. A widely implemented, efficient approach to predicting the initiation of surface RCF damage is the fatigue index (FI), which can be obtained by using the dynamic vehicle/track interaction outputs in Table 8 in a relationship [5]. Any value of the index greater than zero would lead to the formation of surface-initiated RCF cracks. The model is based on the principle that surface cracks are initiated due to the accumulation of plastic damage or ratcheting and includes the value of yield stress in shear of a work-hardened material in the calculation [12]. To predict the cyclic accumulation of fatigue damage for fluctuating loads, the Palmgren-Miner rule for linear damage may be implemented to obtain the proportion of utilised fatigue life in the local region [12]. Assumptions of full slip and Hertzian contact conditions make the model representative only for certain contact conditions. 
Table 8. Summary of different RCF models used with S\&C numerical simulation.

\begin{tabular}{|c|c|c|c|}
\hline Capability & Input Parameters & Limitations & Examples \\
\hline \multicolumn{4}{|c|}{ Shakedown theory index [5] } \\
\hline $\begin{array}{l}\text { Contact locations with risk of } \\
\text { surface-initiated RCF [5]. } \\
\text { Prediction of fatigue life with } \\
\text { Palmgren-Miner rule [122]. }\end{array}$ & $\begin{array}{l}\text { Normal and lateral contact forces. } \\
\text { Contact patch geometry. } \\
\text { Yield shear stress of work-hardened } \\
\text { rail material. }\end{array}$ & $\begin{array}{c}\text { Full slip assumed [12]. } \\
\text { Assumes Hertzian contact } \\
\text { patch [12]. } \\
\text { Does not estimate RCF } \\
\text { damage type [12]. }\end{array}$ & $\begin{array}{c}\text { Switch }[12,20,25,26] . \\
\text { Crossing }[65] . \\
\text { Complete turnout }[22,94] .\end{array}$ \\
\hline \multicolumn{4}{|c|}{ T $\gamma$ number [117] } \\
\hline $\begin{array}{l}\text { Wear/RCF locations using } \\
\text { whole-life rail model [114]. }\end{array}$ & $\begin{array}{l}\text { Creep forces and creepages in } \\
\text { longitudinal, transverse and } \\
\text { spin directions. }\end{array}$ & $\begin{array}{l}\text { Further validation for } \\
\text { S\&Cs suggested [9]. } \\
\text { Does not estimate RCF } \\
\text { damage type [123]. }\end{array}$ & $\begin{array}{l}\text { Crossing [46]. } \\
\text { Complete turnout [94]. }\end{array}$ \\
\hline \multicolumn{4}{|c|}{ Jiang and Sehitoglu (J-S model) [121] } \\
\hline $\begin{array}{l}\text { Fatigue crack initiation location, } \\
\text { plane and cycles to failure [121]. }\end{array}$ & $\begin{array}{l}\text { Maximum normal stress. } \\
\text { Normal strain range. } \\
\text { Shear stress and strain range. } \\
\text { Material fatigue properties. }\end{array}$ & $\begin{array}{l}\text { Inputs to the model } \\
\text { require long } \\
\text { computational times [121]. }\end{array}$ & Crossing [14]. \\
\hline \multicolumn{4}{|c|}{ Surface crack FE model [47] } \\
\hline $\begin{array}{l}\text { Crack growth angle, crack } \\
\text { driving forces and strain energy } \\
\text { at the crack tip [47]. }\end{array}$ & $\begin{array}{l}\text { Total elastic-plastic strain energy. } \\
\text { Crack geometry (initial crack angle). } \\
\text { Maximum contact pressure, contact } \\
\text { patch size and slip. }\end{array}$ & $\begin{array}{l}\text { Propagation of existing } \\
\text { crack without studying } \\
\text { crack initiation [47]. }\end{array}$ & Crossing [47]. \\
\hline \multicolumn{4}{|c|}{ Surface damage indicator model [54] } \\
\hline $\begin{array}{c}\text { Surface RCF damage } \\
\text { development through the } \\
\text { merging of voids until elastic } \\
\text { shakedown (initial cycles) [54]. }\end{array}$ & $\begin{array}{c}\text { Material constant. } \\
\text { Mean hydrostatic stress. } \\
\text { Equivalent Von Mises stress. } \\
\text { Incremental plastic strain vector. } \\
\text { Accumulated equivalent } \\
\text { plastic strain. }\end{array}$ & $\begin{array}{l}\text { Only valid for initial } \\
\text { loading until elastic } \\
\text { shakedown [54]. } \\
\text { Invalid if no tensile } \\
\text { principal stress } \\
\text { components present [54]. }\end{array}$ & Crossing [54]. \\
\hline \multicolumn{4}{|c|}{ Equivalent ratcheting plastic strain [51] } \\
\hline $\begin{array}{l}\text { Fatigue crack initiation by } \\
\text { ratcheting [51]. }\end{array}$ & $\begin{array}{l}\text { Axial and shear ratcheting strains at } \\
\text { every cycle whilst implementing a } \\
\text { non-linear elastic-plastic } \\
\text { material model [51]. }\end{array}$ & $\begin{array}{l}\text { Only valid for low cycle } \\
\text { fatigue [51]. } \\
\text { Lack of validation with } \\
\text { experimental data [51]. }\end{array}$ & Crossing [51]. \\
\hline
\end{tabular}

As previously explained in Section 4.1, the $\mathrm{T} \gamma$ model, which can be used to differentiate between surface wear and RCF-susceptible locations on rails, can also be used to determine the intensity of RCF damage on $S \& C$ rails [115].

An approach to determine the initiation of surface RCF cracks for a crossing rail material for the initial loading cycles until elastic shakedown has been studied [54]. Outputs from an FE model for the variables in Table 8 were used to give the damage indicator number using an appropriate relationship [54]. Damage in the form of micro-crack initiation would be achieved when the damage indicator number reaches unity [54]. The model is limited for damage prediction in the first few material loading cycles and for the prediction of tensile failure [54].

On the contrary, the fatigue life of a crossing material in the ratcheting phase, where plastic deformation is accumulated at every loading cycle, can be obtained by calculating the value of the equivalent ratcheting plastic strain per cycle using the outputs from an FE model [51].

An empirical model introduced by Jiang and Sehitoglu [121] supports the prediction of cracks initiated on the railhead surface/subsurface, by introducing a fatigue damage parameter which can be calculated by post-processing outputs from structural analysis. 
An indication of the critical location of crack initiation along the turnout is identified from the highest value of Von Mises stress. The plane of fatigue crack propagation is obtained through the tensor rotation of stresses/strains at the critical location. A relationship between material fatigue properties and model outputs at the critical location and plane is then solved to estimate the remaining cycles to fatigue crack initiation. The location of fatigue crack initiation for nominal and worn rail profiles would be different, implying that the estimation obtained from the damage prediction model must be implemented for cyclic studies, rather than assuming the results to be an accurate one-off estimation. The surface/subsurface RCF prediction approach is limited by the computational efficiency of the solver used to obtain the inputs for the model [121].

An approach to calculating the propagation of an existing subsurface RCF crack has been implemented [47], where the crack growth amplitude and direction were obtained by calculating the crack growth angle and strain energy at the crack tip through a $2 \mathrm{D} F E$ crossing model with the crack geometry. The model is limited to studying the propagation of an existing crack without prediction of crack initiation. It has been observed that RCF damage such as squats can also be incorporated into the rail geometry to study its effect on dynamic response outputs [62].

Modelling approaches used to predict the propagation of surface-initiated RCF can be inherently used to predict the development of Category 2 faults such as fracture in the rail foot. However, the direct prediction of fatigue and fracture of the rail web and foot can be obtained more accurately through modelling approaches for predicting plasticity, as highlighted in Section 4.3.

A summary of the modelling aspects of the most commonly used RCF prediction models for S\&Cs along with references to examples in the literature is provided in Table 8.

\subsection{Plastic Deformation Prediction Models}

In the literature, models predicting the plastic deformation of $S \& C$ rails have either focused on assessing the material response beyond the elastic limit on high-impact loading over a single cycle, or on studying the cyclic accumulation of subsurface plastic damage. Approaches focused on plastic damage resulting in RCF cracks are discussed in Section 4.2. The modelling approaches discussed in this section may be used to predict Category 1 faults whose root cause is the failure mechanism of plastic deformation as well as Category 2 faults such as fracture of the rail foot.

Plastic deformation due to high-impact loads, resulting in stresses beyond the yield limit, can be obtained from the Von Mises yield criterion [66]. Whilst considering the effect of normal and shear traction on the rail, an indication of a higher value of Von Mises stress than the yield strength in all three dimensions can be used to obtain locations of plastic deformation [71]. Some examples in the literature simplify the Von Mises criterion by excluding the shear components, whilst the majority consider both normal and shear components. Equivalent plastic strain is a scalar variable based on the Von Mises yield criterion, which is capable of representing locations that undergo plastic deformation [71].

In regions with high stress concentrations, crossing subsurface damage due to high cycle fatigue has been predicted by implementing the Dang Van criterion [48,124]. Although this criterion has been used to study the initiation and propagation of surface RCF cracks, the model has also been used to obtain regions with potential plastic deformation across the crossing rail subsurface [48]. Since the model formulation is for high cycle fatigue, the calculation of the Dang Van damage number would demand outputs of stabilised microscopic variables obtained after elastic shakedown to predict an accurate estimate of damage initiation [48]. Moreover, since the initiation of damage depends on the equivalent stress exceeding the shear-torsion fatigue limit, an accurate estimation of damage initiation would demand the use of a calibrated elastic-plastic material model [48].

Load tests have been performed on various grades of rail steel to capture material characteristics for use in cyclic material models. The accumulation of plastic strains in subsurface rail obtained from wheel/rail interaction models has been studied to predict 
plastic deformation whilst considering non-linear elastic-plastic hardening material behaviour. A model to capture the accumulation of cyclic plasticity was developed by Ohno and Wang [125], where the accumulation of plastic strain considers a plastic multiplier parameter derived from the loading condition, deviatoric stress and kinematic hardening. Many FE models in the literature implement material non-linearity through the cyclic Chaboche model with combined isotropic and kinematic hardening [126]. The influence of non-linear elastic-plastic material behaviour and cyclic hardening on the accuracy of damage results is discussed in Section 5.3. A summary of modelling aspects for the most commonly used approaches to predict plastic deformation for S\&Cs along with references to examples in the literature is provided in Table 9.

Table 9. Summary of different models for plastic deformation used with S\&C numerical simulation.

\begin{tabular}{|c|c|c|c|}
\hline Capability & Input Parameters & Limitations & Reference Examples \\
\hline \multicolumn{4}{|c|}{ Von Mises yield criterion [71] } \\
\hline $\begin{array}{l}\text { S\&C locations with } \\
\text { stresses beyond the } \\
\text { yield limit. }\end{array}$ & $\begin{array}{l}\text { Normal stresses and shear traction } \\
\text { in all dimensions. } \\
\text { Representative material properties. }\end{array}$ & $\begin{array}{l}\text { Limited by choice of material model } \\
\text { and the efficiency of the solver. }\end{array}$ & $\begin{array}{c}\text { Switch [68]. } \\
\text { Crossing }[53,57,65-67] .\end{array}$ \\
\hline \multicolumn{4}{|c|}{ Equivalent plastic strain [71] } \\
\hline $\begin{array}{l}\text { Rail locations with } \\
\text { plastic deformation. }\end{array}$ & Plastic material properties. & $\begin{array}{l}\text { Limited by material model choice. } \\
\text { Poor efficiency of FE models limits it to } \\
\text { single cycle. }\end{array}$ & Crossing [45,54-56]. \\
\hline \multicolumn{4}{|c|}{ Dang Van criterion $[48,124]$} \\
\hline $\begin{array}{l}\text { Subsurface rail } \\
\text { plastic deformation } \\
\text { due to high } \\
\text { cycle fatigue. }\end{array}$ & $\begin{array}{l}\text { Shear stress amplitude and } \\
\text { hydrostatic stress at every } \\
\text { time step [48]. } \\
\text { Shear-torsion and } \\
\text { tension-compression } \\
\text { fatigue limits [48]. }\end{array}$ & $\begin{array}{l}\text { Negative stress ratios propose a } \\
\text { different failure limit [48]. } \\
\text { Conservative for certain contact/slip } \\
\text { conditions. [48]. } \\
\text { Fatigue limit overestimated by } \\
\text { hydrostatic stress components [ } 48] \text {. } \\
\text { FE requires simplifications for } \\
\text { improving efficiency. }\end{array}$ & Crossing [48]. \\
\hline \multicolumn{4}{|c|}{ Plastic strain cyclic accumulation [125] } \\
\hline $\begin{array}{l}\text { Plastic deformation } \\
\text { accumulation in } \\
\text { S\&C rails. }\end{array}$ & $\begin{array}{l}\text { Updated material model after } \\
\text { each cycle. } \\
\text { Material hardening test data. }\end{array}$ & $\begin{array}{l}\text { FE requires simplification for cyclic } \\
\text { prediction }[18,25] \text {. } \\
\text { Representative material model difficult. }\end{array}$ & $\begin{array}{l}\text { Switch }[25,74,127] \text {. } \\
\text { Crossing }[18,54,75]\end{array}$ \\
\hline
\end{tabular}

\section{Discussion}

In the previous sections, numerical simulation approaches for dynamic vehicle/track interaction, wheel/rail contact models and rail damage prediction models for S\&Cs are introduced. The contents of this section discuss the factors that govern the choice of an appropriate modelling approach.

\subsection{Consideration of Vehicle Dynamics}

A complex model of the entire train is usually considered in an MBS to take into account the dynamics of the car body and the bogies and capture a more correct wheelset trajectory for the entire train to obtain representative contact locations and forces, which are key parameters for damage prediction. Conversely, vehicle dynamics is usually neglected in FE models, but a more detailed material degradation model considering elastic-plastic behaviour and fatigue failure can be implemented. Detailed stress distribution can also be used for better damage prediction.

In the literature, many FE models considering wheel/S\&C rail contact have been developed with a single wheel/rail, as shown in Figure 3. Computational efficiency is improved with this approach; however, at the expense of the accurate consideration of lateral dynamic behaviour of the vehicle and turnout, especially in the diverging route. 
Consideration of a single wheel has been shown to provide inaccurate assumptions such as negligible slip, as well as low lateral and longitudinal tangential forces [54]. It has been noticed that stability of the wheel is better maintained through the consideration of a complete wheelset; otherwise, additional constraints have to be incorporated for accurate simulation whilst considering a single wheel [45].

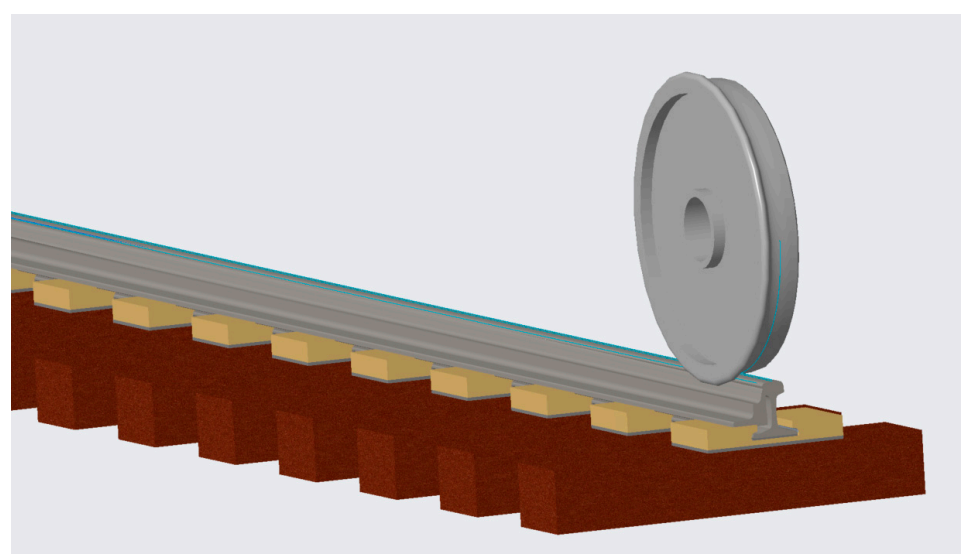

Figure 3. Solid element half-track switch model with a single wheel.

Dynamic interaction between a complete wheelset and switch/crossing panels has also been carried out, as shown in Figure 4. A representative trajectory may be obtained without the requirement for displacement constraints if a complete wheelset is considered [64]. However, although such models consider a more detailed lateral dynamic effect than a single wheel, they neglect lateral dynamics caused by the bogie and the car body connections.

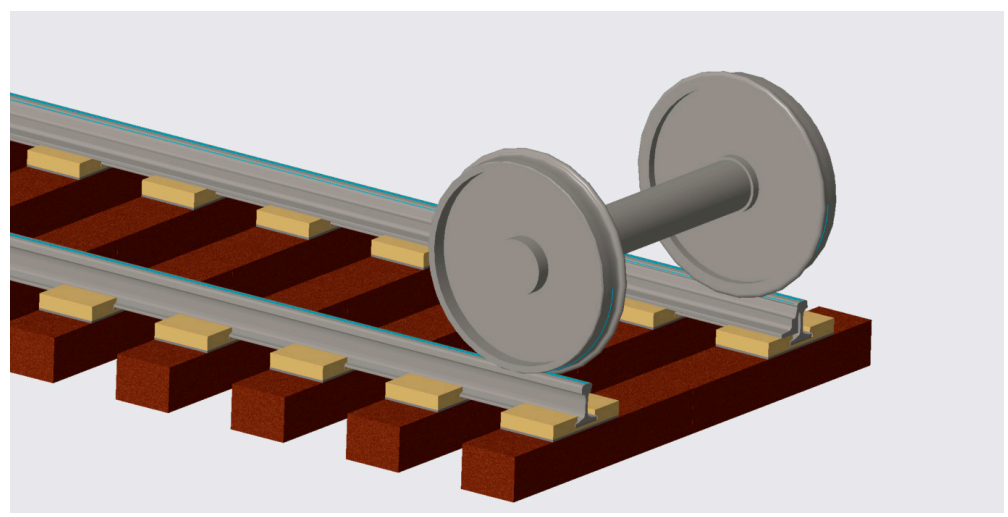

Figure 4. Solid element full-track switch model with one wheelset.

Recently, in a combined simulation approach, vehicle-track interaction was modelled using an MBS and the Hertzian contact force and patches were used as inputs at the same contact location on the rail head of a 3D solid element FE model to analyse rail accelerations [88]. The approach introduced an efficient way of considering vehicle dynamics, but with certain limitations. Uneven stress distributions in the elliptical contact patch were ignored, tangential contact behaviour was simulated as a sliding load and the effect of lateral displacement was ignored [88]. On the other hand, improved efficiency through the inclusion of a single wheel as well as representative wheel motions can be achieved in FE simulations through the inclusion of appropriate wheel and rail displacement motions obtained from an MBS model considering complete vehicle dynamics into a sub-FE model. In this way, a detailed representation of vehicle dynamics as well as appropriate material behaviour in rail surface and subsurface regions can be considered for damage prediction. 
However, it must be ensured that the track dynamics between the MBS and FE models are calibrated. Due to a lower-frequency response, the influence of sprung mass on contact between the wheelset and switch panel is low but not negligible [44]. Therefore, many examples in the literature have considered vehicle dynamics up to the primary suspension and have simplified the secondary suspension along with the carriage and bogies as a lumped mass. Unlike the load transition zone at the switch, which is smoother, wing rail to crossing transition has discontinuities. Therefore, impact in a higher frequency range cannot be avoided. The consideration of lower-frequency vehicle dynamics becomes less important and the secondary suspension has a negligible effect on wheel-rail contact [108].

Numerical simulations can be carried out through the direct application of contact loads on S\&C rails, without including wheelset geometry. Such models are primarily focused on analysing substructure behaviour and hence do not require detailed wheel-rail contact modelling, helping to achieve acceptable computational efficiency for FE models whilst considering a complete track model for longer turnout lengths $[69,70]$.

\subsection{Consideration of Track Dynamics}

The consideration of the effects of substructure or track stiffness is an important aspect since it influences the amplitude of impact forces on the rail. Rail deflection is influenced by the material properties of the railpad/ballast. Additionally, the distribution of loads on the rail as well as stress distribution from the superstructure to substructure is influenced by the space between sleepers [109]. For a combined MBS-FE modelling approach [16], the values of impact loads/wheelset displacement obtained from a supported MBS track model were substituted into an FE model that had no bedding, potentially affecting the accuracy of results. In reality, a lower bedding stiffness would allow for more vertical rail deflection, resulting in greater axle load distribution over the sleepers, as opposed to a rigid track with higher track stiffness [109]. Therefore, in the case of MBS/FE combined models, superstructure and bedding properties should be calibrated between the MBS and FE models.

Higher-frequency track dynamics can be considered with more accuracy by multilayer MBS track models with multiple DOF than single-layer co-running track models [42]. Moreover, the separation of bedding components and variation of the properties of individual rail/trackbed components is possible in a multi-layer, multiple-DOF co-running track model. In FE, the substructure has either been simplified by using rigid elements or by considering a detailed solid element substructure. The calibration of FE track properties against MBS models and field measurements can be achieved by adjusting the material properties to obtain similar rail receptance results [128].

\subsection{Consideration of Representative Material Properties}

It has been shown that material property choice influences the contact patch size and stress distribution [89], wear/RCF surface damage distributions [20] and subsurface damage/Von Mises stress distributions in regions with plastic deformation [53]. The consideration of perfectly plastic material behaviour to study MBS interaction between vehicle and plain line rail has been implemented for the semi-Hertzian [107] and multiHertzian methods but without material hardening [113]. Comparable results from the studies were obtained for elastic-plastic steady-state FEM analyses, with larger contact patch sizes and reduced contact stress values obtained for the perfectly plastic material than elastic material properties [113]. A Hertzian-based meta-modelling approach that considers cyclic elastic-plastic hardening material behaviour has been implemented for the cyclic degradation prediction of crossings [49]. Further experimental validation of this model has been suggested.

For ductile materials, when elastic-plastic material behaviour is considered beyond the elastic limit, higher strains are obtained for the same increase in stress than in the linear elastic region. Thus, if linear elastic material behaviour is considered, the value of stresses in the regions with plastic deformation would be overestimated, thus affecting the accuracy 
of damage prediction [53]. Elastic-plastic material behaviour along with hardening has been considered in S\&C rails for all of the reviewed FE wheel/rail contact models used for damage prediction. In the majority of the literature surveyed, the wheel is modelled using linear elastic material behaviour. The reasons for this simplification are the lack of hardening data available for wheel material [48] and the assumption of the simulation of cyclic passages with new wheels [54]. Models with the direct application of load on a complete $S \& C$ turnout without the consideration of wheel geometry assume linear elastic material for $S \& C$ rails $[69,70]$, since these models either focus on the substructure [69] or vehicle dynamics [70].

\subsection{Computational Efficiency for Numerical Simulation of SECS}

The efficiency of a numerical simulation approach depends on the complexity of the developed model, but commonly, MBS models are the quickest, followed by modal reduction flexible track, combined MBS-FE and solid element FE models. The computational efficiency of empirical wheel-rail contact models, from quickest to slowest, is in the order Hertzian method, multi-Hertzian methods, semi-Hertzian methods and Kalker's CONTACT boundary element model, with the slower models showing more representative results. Elastic-plastic contact models are slower than elastic models for the same contact method $[107,113]$.

Track dynamics can also be simplified for models focusing on vehicle performance [35], as well as wheel damage [36], by modelling the wheel-rail contact patch as linear springs and giving each wheelset one vertical and lateral DOF [36,37]. A method to simplify modelling the distinction between stock and switch rails changes the value of contact stiffness for the latter into half the value of the former for two-point contact in the transition region [36].

Empirical damage prediction models can be used in a post-processing step to obtain efficient damage predictions. Detailed cyclic damage studies using the FEA approach are limited by computational efficiency, which can be improved by selective meshing, geometry simplification, plane stress/strain assumption or sub-modelling.

\subsection{Different Frequency Ranges for Fault Simulation}

Material failure generally occurs due to high lateral and normal contact forces during stock-switch and wing rail-crossing nose transitions, respectively.

The contribution of higher frequencies to maximum normal contact forces for crossings and maximum lateral contact forces for switches has been investigated [17]. On plotting the maximum vertical contact force on the crossings in the frequency domain, it was found that the outputs obtained at lower frequencies $(0-100 \mathrm{~Hz})$ are considerably lower than those obtained at higher frequencies $(800-1000 \mathrm{~Hz})$ [17]. Appropriate normal contact behaviour plays an important role in quantitative damage prediction modelling and is a variable that has been frequently included in damage prediction models. This calls for the capture of dynamic outputs at a wider frequency range in crossings to appropriately predict the dominant crossing failure mechanisms of RCF and fracture. For railway switches, the dominant failure mechanism is wear [129], which is influenced more by lateral contact forces [115]. By plotting the maximum lateral contact forces on the switch rail in the frequency domain, it has been shown that the effect of higher frequencies on the result is minimal [17]. Therefore, efficient modelling approaches that can consider this lower frequency range of interest can be used for the prediction of wear.

However, it has to be recognised that switches can undergo flange contact as well as consisting of discontinuities when deformed, in which case the effect of considering higher frequencies would become important. Therefore, dynamics outputs in the appropriate frequency range should be investigated for accurate prediction of damage at these locations. FEA models can effectively capture higher-frequency content, but commonly used MBS models with a single track layer are generally limited to low frequencies up to $20 \mathrm{~Hz}$ [17]. In the literature, MBS models with multiple track layers with higher DOF have 
been tuned to effectively capture higher-frequency content up to $200 \mathrm{~Hz}[18,75]$. Different track layers affect the track stiffness at different frequencies of interest. For example, one track resonance is generally obtained between 50 to $300 \mathrm{~Hz}$ due to the vibration of the track on the ballast bed [109]. Another is obtained between 200 and $600 \mathrm{~Hz}$ due the vibration of the rail over the railpad [109]. Therefore, finer tuning of the track receptance is possible if multiple track layers are considered. Where a single-layered track model was tuned against the stiffness data obtained from the field at $10 \mathrm{~Hz}$ [42], very high track stiffness was obtained at higher frequencies since the viscous damping had to be high for the single bedding layer for data fitting in the frequency range of interest. Therefore, good consideration of track flexibility helps consider appropriate track stiffness behaviour across a wide range of frequencies. Although inputs of contact forces to the contact models can be estimated at higher frequencies, the determination of contact patch size and pressure using wheel-rail contact models only considers quasi-static conditions and lower-frequency track dynamics. Therefore, it is assumed that a given contact force input to the contact model, whether that be due to high-frequency impact or higher static loading, would result in the same distribution of contact patch size and pressures. The variation of rail properties in a longitudinal direction and field calibration influence field replicability. The calibration of MBS track models against the field can be carried out, as shown in [18], where field substructure properties were replicated by calibrating the rail receptance values in the model up to $200 \mathrm{~Hz}$. Good agreement of the results obtained proved the usefulness of adding more layers to the co-running track model to give reasonable results [18]. Field measurements of track stiffness have been carried out in the frequency range up to $20 \mathrm{~Hz}$ using a rolling stiffness measurement vehicle (RSMV) $[42,130]$ and an appropriate relationship has been developed for their conversion to substructure dynamic properties for single and two-layered S\&C track models [42]. Normal and lateral wheel/rail contact forces have been measured in the field using wheelsets instrumented with strain-gauge bridges and used to compare the results obtained from the single and two-layered MBS track model [42], demonstrating the ability of multi-layer track models to capture more representative results. Higher-frequency content could also be captured by implementing beam/solid element FE models as well as models based on FE modal reduction.

\subsection{Methods of Model Validation}

Many models in the reviewed literature were validated against field measurements through the comparison of dynamic outputs with more established models. A common form of validation is the comparison of qualitative results of dynamic outputs such as normal and lateral contact forces and Von Mises stress against corresponding outputs from validated models in the literature. Direct validation includes comparing simulation contact forces and rail accelerations with field measurements $[42,59,64,130]$, the comparison of measured and simulated transition regions [59] and the comparison of degradation (wear/plastic deformation) depth against field measurements $[19,65]$ as well as sleeper displacements [81]. Calibration-based model validation includes fine-tuning of material properties against load tests as well as the calibration of substructure dynamics using rail receptance $[29,42,128]$. This has been carried out in MBS approaches by selecting the appropriate values for stiffness and damping coefficients for track models with a different number of bedding layers.

Worn switch rail profiles, side wear and worn area measured in the field were compared with corresponding outputs from MBS simulations and Archard's wear model for a passage of 100 million tonnes $(\mathrm{mt})$ [19]. It could be observed from the tabulated results that estimations from the simulation results were close to field measurements of side wear and worn area. The results were underestimated considerably by the simulations at the switch tip and by less than $10 \%$ for locations far away from the switch tip. The underestimation of wear near the switch tip by using the MBS approach was due to contact occurring between rigid bodies of the wheel and switch tip only after tremendous wear of the stock rail, 
whereas real-life operation involves dynamic relative displacement between the stock and switch rails with an increased risk of wheel flange contact [19].

The comparison of the prediction of wear and plastic deformation from FE simulations was carried out against degradation measured by field measurements after the passage of 15.10 million gross tonnes (MGT) of rail traffic [66]. The regions where severe wear and plastic deformation were observed in the field were similar to the predictions obtained using Archard's wear model and Von Mises yield criterion in the simulations. Moreover, the RCF fault of spalling was observed in the diverging direction from field measurements [66]. Stresses obtained from the FE simulation in the diverging route around the vicinity of the fault occurrence were considerably higher than in the through route, demonstrating the potential of numerical simulations to predict specific RCF faults [66]. It can thus be concluded that degradation locations have been effectively predicted for different $S \& C$ layouts using these damage prediction models.

\section{Summary of Conclusions}

This article assesses the different approaches used to model vehicle/track interaction, wheel-rail contact and damage prediction for S\&C rails. These independent modelling components need to be combined appropriately to predict different $S \& C$ failure modes.

The choice of a numerical simulation approach to predict $S \& C$ damage involves three important decisions. The first decision is the choice of an appropriate damage prediction model. The drawbacks of the empirical relationships implemented to predict S\&C damage mechanisms have been assessed. Among empirical relationships to predict rail surface damage, the Archard wear model is a well-used and validated approach for predicting local wear in a discretised contact patch but cannot be used without discretisation for calculating wear globally in a contact patch since spin would not be taken into account [119]. The values of $\mathrm{T} \gamma$ for damage prediction through the whole-life rail model are only valid for tested and calibrated rail materials. Since the FI index for surface-initiated RCF prediction assumes ratcheting or plastic deformation at every loading cycle, a conservative estimate of damage would be obtained in regions that are susceptible to high cycle fatigue in S\&Cs. Although the amplitude of damage obtained from empirical models needs more investigation and validation, these models can still suitably indicate the locations with expected surface rail damage [25]. More representative predictions of the low and high cycle fatigue life of $S \& C$ rails can be carried out by implementing non-linear elastic-plastic material properties for $\mathrm{S} \& \mathrm{C}$ rails. For a single wheel passage, plastic deformation can be predicted by implementing an appropriate yield criterion, inspecting stresses higher than the yield limit or by examining scalar plastic strain values [71]. The choice of an appropriate damage prediction model must be made after assessing the accuracy and efficiency requirements to obtain the solution.

The second decision is the choice of an appropriate numerical simulation approach for the vehicle/track interaction to obtain the outputs needed for predicting the damage mechanism. The choice of an appropriate numerical simulation approach is governed by factors such as the frequency range of interest, analysis of subsurface mechanical behaviour, consideration of non-linear material behaviour and computational efficiency.

The vehicle/track interaction model should be able to capture dynamic outputs up to an appropriate frequency range at the damage location of interest. At locations with fewer discontinuities, MBS models with a single track layer can capture accurate low-frequency dynamic outputs for damage prediction models. However, dynamic interaction in higherfrequency impact regions should be studied using multi-layer track models. FE models or flexible track models based on the modal reduction approach are capable of capturing dynamic response outputs in a higher frequency range.

Detailed non-linear elastic-plastic material behaviour along with cyclic hardening effects can be considered in FE models. Flexible track models based on the modal reduction approach are limited to considering the linear material behaviour of the structure. The consideration of material behaviour in MBS is influenced by the wheel/rail contact model. 
A meta-modelling approach, implementing calibrated non-linear material behaviour with cyclic hardening, has been developed for wheel/rail contact. Although dynamic vehicle/track interaction outputs obtained from MBS simulations can be used as inputs to the meta-model, further validation of the approach has been suggested [18].

If an estimation of output variables at different locations in the rail subsurface is needed, solid element FE models, as well as flexible track models implemented through modal reduction in FE solid elements, could be used to obtain the necessary outputs. The implementation of the MBS and beam element FE approach is limited to considering dynamic behaviour.

Ultimately, the choice of a modelling approach for dynamic vehicle/track interaction is dependent on the efficiency and the requirement for cyclic simulation. Traditionally, either MBS models for the complete vehicle/turnout interaction or FE models for interaction between the unsprung mass and smaller section of the $S \& C$ track have been the preferred modelling approaches. Both these approaches either consider the effect of vehicle dynamics or S\&C track mechanical behaviour in detail. Acceptably efficient consideration of both of those effects is possible with the modal reduction approach. Although there are limitations associated with cyclic predictions, such as updating of geometry and material non-linearity, more accurate contact loads in the appropriate frequency range of interest to predict failure modes using empirical damage prediction models may be obtained through this approach in relation to MBS modelling. Outputs of subsurface variables may also be obtained if a solid element flexible track model is considered. Similar to the modal reduction approach, MBS-FE combined simulation considers the effects of the vehicle as well as track dynamics whilst also accounting for non-linear material behaviour, but with poor efficiency.

The selection of an appropriate numerical simulation approach is followed by the third decision, the choice of a wheel/rail contact modelling approach. A representative contact point detection mechanism and good accuracy of the wheel-rail contact model is needed to estimate the transfer of normal and lateral contact forces and pressures from the wheel to $S \& C$ rails. Hertzian-based normal contact models used in MBS approaches give a good estimate of contact forces and pressures on plain line track where there are no discontinuities. However, profile changes, multiple-point contacts and asymmetric contact areas make S\&Cs different from plain line track and many contact modelling assumptions become invalid. Another consideration is contact elastoplasticity, which affects the contact patch area and pressure and is considered in FE with greater accuracy.

Tangential contact modelling solutions used in MBS have been optimised for applicability in railways and thus consider creep components in different DOF in greater detail, whereas FEA solutions implement simpler frictional models. Greater efficiency has been achieved where the direct substitution of concentrated loads instead of loading through a contact patch is acceptable, such as in cases where the model's focus is on analysing the mechanical behaviour of the substructure or far from the rail surface.

It has been justified through the evaluation that MBS models provide efficient and accurate surface damage predictions under conditions of low-frequency track dynamics in switches. The suitability of solid element FE models has been justified for subsurface damage prediction and for considering non-linear elastic-plastic material behaviour and the effect of loading at higher frequencies in crossings. The suitability of beam element flexible-track modal reduction models has been justified for the prediction of surface damage at locations with high-frequency impact loading in S\&Cs.

It has been recognised that the flexible track modelling approach using modal reduction, which has been used more for modelling research interests and sparsely for S\&C damage predictions, has good potential for being used for the prediction of surface rail damage. In a few examples in the literature where a combination of independent MBS and FE models have been used, the vehicle and track substructure dynamics have not been calibrated between the two independent models. The replication of track stiffness through the calibration of rail receptance and the appropriate consideration of vehicle dynamics in FE sub-model simulations through the replication of wheel movement are 
suggested. It has been recognised that although representative dynamic contact forces can be captured by models in a wide range of frequencies, wheel-rail contact patch modelling does not consider the effect of high-frequency dynamics in the calculation of contact patch distributions and pressures. It is suggested that a better investigation into the influence of high-frequency dynamics on the contact patch is performed and that the current models are improved after the influence of higher frequencies has been assessed.

Following this evaluation, future work will include the development of a combined MBS-FE simulation approach to modelling switch degradation, with the outputs of an efficient MBS model informing the selection of the location of a detailed sub-FE model whilst replicating the vehicle and track dynamic behaviour between the two independent models. This article has brought together information from various sources on numerical simulation approaches for the prediction of the main $S \& C$ rail degradation mechanisms, as well as discussing the important considerations involved whilst selecting an appropriate numerical simulation approach. Risk-informed decisions for the predictive maintenance of S\&Cs may be made during the S\&C design or renewal phase by accounting for the expected traffic flow and obtaining the expected damage locations on turnouts with numerical simulations. Useful information can be made available for asset managers if the first principles of asset degradation are taken into account to improve the estimation of railway asset dependability. An evaluation of the dependability of railway vehicles was carried out [131], where the actual operating conditions of the rolling stock components, pantographs in particular, were considered. The closest relationship between the structural dependability, safety factor and probability distributions of stresses contributing to wear was determined [131]. Similar approaches can be adopted for tracks, particularly S\&Cs, where degradation due to contact conditions is considerable. In addition to existing health monitoring systems, the estimation of the degradation location and wear/fatigue life through numerical simulations may also be used whilst considering live railway traffic to support predictive maintenance for S\&Cs. To this end, this article has presented and discussed collective information to foster further research in this field.

Author Contributions: Conceptualization, N.P.; writing-original draft preparation, N.P.; writingreview and editing, N.P. and J.-Y.S.; visualization, N.P.; supervision, J.-Y.S. and C.R.; project administration, C.R.; funding acquisition, C.R. All authors have read and agreed to the published version of the manuscript.

Funding: The work described has been supported by the S-CODE project. This project has received funding from the Shift2Rail Joint Undertaking under the European Union's Horizon 2020 research and innovation programme under grant agreement No. 730849. This publication reflects only the authors' view, and the Shift2Rail Joint Undertaking is not responsible for any use that may be made of the information it contains.

Data Availability Statement: Data sharing not applicable. No new data were created or analyzed in this study.

Conflicts of Interest: The authors declare no conflict of interest.

\section{References}

1. Cornish, A.T. Life-Time Monitoring of in Service Switches and Crossings through Field Experimentation. Ph.D. Thesis, Imperial College London, London, UK, 2014.

2. Olofsson, U.; Zhu, Y.; Abbasi, S.; Lewis, R.; Lewis, S. Tribology of the wheel-rail contact-aspects of wear, particle emission and adhesion. Veh. Syst. Dyn. 2013, 51, 1091-1120. [CrossRef]

3. Grossoni, I.; Hughes, P.; Bezin, Y.; Bevan, A.; Jaiswal, J. Observed failures at railway turnouts: Failure analysis, possible causes and links to current and future research. Eng. Fail. Anal. 2021, 119, 104987. [CrossRef]

4. Capacity4Rail. Deliverable Report D13.1: Operational Failure Modes of Switches and Crossings; European Commission: Brussels, Belgium, 2015.

5. Ekberg, A.; Åkesson, B.; Kabo, E. Wheel/rail rolling contact fatigue-Probe, predict, prevent. Wear 2014, 314, 2-12. [CrossRef]

6. Yang, R.; Cao, S.; Kang, W.; Li, J.; Jiang, X. Mechanism Analysis of Spalling Defect on Rail Surface under Rolling Contact Conditions. Math. Probl. Eng. 2018, 2018. [CrossRef] 
7. Ringsberg, J.W.; Bjarnehed, H.; Johansson, A.; Josefson, B.L. Rolling contact fatigue of rails-Finite element modelling of residual stresses, strains and crack initiation. Proc. Inst. Mech. Eng. Part F J. Rail Rapid Transit 2000, 214, 7-19. [CrossRef]

8. Kaewunruen, S.; Ishida, M.; Marich, S. Dynamic wheel-rail interaction over rail squat defects. Acoust. Aust. 2015, 43, 97-107. [CrossRef]

9. Coleman, I. The Development of Modelling Tools for Railway Switches and Crossings. Ph.D. Thesis, Imperial College London, London, UK, 2014.

10. Grassie, S.L.; Kalousek, J. Rail Corrugation: Characteristics, Causes and Treatments. Proc. Inst. Mech. Eng. Part F J. Rail Rapid Transit 1993. [CrossRef]

11. Grassie, S.L. Rail corrugation: Characteristics, causes, and treatments. Proc. Inst. Mech. Eng. Part F J. Rail Rapid Transit 2009, 223, 581-596. [CrossRef]

12. Nielsen, J.C.O.; Pålsson, B.A.; Torstensson, P.T. Switch panel design based on simulation of accumulated rail damage in a railway turnout. Wear 2016, 366-367, 241-248. [CrossRef]

13. Brouzoulis, J.; Torstensson, P.T.; Stock, R.; Ekh, M. Prediction of wear and plastic flow in rails-Test rig results, model calibration and numerical prediction. Wear 2011, 271, 92-99. [CrossRef]

14. Xin, L.; Markine, V.L.; Shevtsov, I.Y. Numerical procedure for fatigue life prediction for railway turnout crossings using explicit finite element approach. Wear 2016, 366-367, 167-179. [CrossRef]

15. Li, S.; Li, Z.; Núñez, A.; Dollevoet, R. New insights into the short pitch corrugation enigma based on 3D-FE coupled dynamic vehicle-track modeling of frictional rolling contact. Appl. Sci. 2017, 7, 807. [CrossRef]

16. Xu, J.; Wang, P.; Wang, L.; Chen, R. Effects of profile wear on wheel-rail contact conditions and dynamic interaction of vehicle and turnout. Adv. Mech. Eng. 2016, 8, 1-14. [CrossRef]

17. Kassa, E.; Nielsen, J.C.O. Dynamic train-turnout interaction in an extended frequency range using a detailed model of track dynamics. J. Sound Vib. 2009, 320, 893-914. [CrossRef]

18. Skrypnyk, R.; Ekh, M.; Nielsen, J.C.O.; Pålsson, B.A. Prediction of plastic deformation and wear in railway crossings-Comparing the performance of two rail steel grades. Wear 2019, 428-429, 302-314. [CrossRef]

19. Wang, P.; Xu, J.; Xie, K.; Chen, R. Numerical simulation of rail profiles evolution in the switch panel of a railway turnout. Wear 2016, 366-367, 105-115. [CrossRef]

20. Ma, X.; Wang, P.; Xu, J.; Chen, R.; Wang, J. Assessment of non-Hertzian wheel-rail contact models for numerical simulation of rail damages in switch panel of railway turnout. Wear 2019, 432-433, 648-657. [CrossRef]

21. Pålsson, B.A.; Nielsen, J.C.O. Wheel-rail interaction and damage in switches and crossings. Veh. Syst. Dyn. 2012, 50, 43-58. [CrossRef]

22. Karttunen, K.; Kabo, E.; Ekberg, A. Estimation of gauge corner and flange root degradation from rail, wheel and track geometries. Wear 2016, 366-367, 294-302. [CrossRef]

23. Xu, J.; Wang, P.; Wang, J.; An, B.; Chen, R. Numerical analysis of the effect of track parameters on the wear of turnout rails in high-speed railways. Proc. Inst. Mech. Eng. Part F J. Rail Rapid Transit 2018, 232, 709-721. [CrossRef]

24. Hiensch, E.J.M.; Burgelman, N. Switch Panel wear loading-a parametric study regarding governing train operational factors. Veh. Syst. Dyn. 2017, 55, 1384-1404. [CrossRef]

25. Johansson, A.; Pålsson, B.; Ekh, M.; Nielsen, J.C.O.; Ander, M.K.A.; Brouzoulis, J.; Kassa, E. Simulation of wheel-rail contact and damage in switches \& crossings. Wear 2011, 271, 472-481. [CrossRef]

26. Ma, X.; Wang, P.; Xu, J.; Chen, R. Parameters studies on surface initiated rolling contact fatigue of turnout rails by three-level unreplicated saturated factorial design. Appl. Sci. 2018, 8, 461. [CrossRef]

27. Burgelman, N.; Li, Z.; Dollevoet, R. A new rolling contact method applied to conformal contact and the train-turnout interaction. Wear 2014, 321, 94-105. [CrossRef]

28. Kassa, E.; Andersson, C.; Nielsen, J.C.O. Simulation of dynamic interaction between train and railway turnout. Veh. Syst. Dyn. 2006, 44, 247-258. [CrossRef]

29. Lau, A.; Hoff, I. Simulation of Train-Turnout Coupled Dynamics Using a Multibody Simulation Software. Model. Simul. Eng. 2018, 2018. [CrossRef]

30. Bezin, Y.; Kostovasilis, D.; Sambo, B. Relative Movement of Switch/Stock Rails and the Wheel/Rail Interaction Interface. In Lecture Notes in Mechanical Engineering, Advances in Dynamics of Vehicles on Roads and Tracks (IAVSD 2019), Gothenburg, Sweden, 12-16 August 2019; Klomp, M., Bruzelius, F., Nielsen, J., Hillemyr, A., Eds.; Springer: Cham, Switzerland, 2020 ; pp. 367-375.

31. Liu, X.; Markine, V.L. Train hunting related fast degradation of a railway crossing-condition monitoring and numerical verification. Sensors 2020, 20, 2278. [CrossRef] [PubMed]

32. Wang, P.; Ma, X.; Xu, J.; Wang, J.; Chen, R. Numerical investigation on effect of the relative motion of stock/switch rails on the load transfer distribution along the switch panel in high-speed railway turnout. Veh. Syst. Dyn. 2019, 57, 226-246. [CrossRef]

33. Pålsson, B.A. A linear wheel-crossing interaction model. Proc. Inst. Mech. Eng. Part F J. Rail Rapid Transit 2018, 232, 2431-2443. [CrossRef]

34. Bezin, Y.; Sarmiento-Carnevali, M.L.; Sichani, M.S.; Neves, S.; Kostovasilis, D.; Bemment, S.D.; Harrison, T.J.; Ward, C.P.; Dixon, R. Dynamic analysis and performance of a repoint track switch. Veh. Syst. Dyn. 2020, 58, 843-863. [CrossRef]

35. Lagos, R.F.; Alonso, A.; Vinolas, J.; Pérez, X. Rail vehicle passing through a turnout: Analysis of different turnout designs and wheel profiles. Proc. Inst. Mech. Eng. Part F J. Rail Rapid Transit 2012, 226, 587-602. [CrossRef] 
36. Casanueva, C.; Doulgerakis, E.; Jönsson, P.A.; Stichel, S. Influence of switches and crossings on wheel profile evolution in freight vehicles. Veh. Syst. Dyn. 2014, 52, 317-337. [CrossRef]

37. Sun, Y.Q.; Cole, C.; Boyd, P. A numerical method using VAMPIRE modelling for prediction of turnout curve wheel-rail wear. Wear 2011, 271, 482-491. [CrossRef]

38. Nicklisch, D.; Kassa, E.; Nielsen, J.; Ekh, M.; Iwnicki, S. Geometry and stiffness optimization for switches and crossings, and simulation of material degradation. Proc. Inst. Mech. Eng. Part F J. Rail Rapid Transit 2010, 224, 279-292. [CrossRef]

39. Pålsson, B.A. Design optimisation of switch rails in railway turnouts. Veh. Syst. Dyn. 2013, 3114, 37-41. [CrossRef]

40. Pålsson, B.A.; Nielsen, J.C.O. Track gauge optimisation of railway switches using a genetic algorithm. Veh. Syst. Dyn. 2012, 50, 365-387. [CrossRef]

41. Pålsson, B.A. Optimisation of railway crossing geometry considering a representative set of wheel profiles. Veh. Syst. Dyn. 2015, 53, 274-301. [CrossRef]

42. Pålsson, B.A.; Nielsen, J.C.O. Dynamic vehicle-track interaction in switches and crossings and the influence of rail pad stiffnessField measurements and validation of a simulation model. Veh. Syst. Dyn. 2015, 53, 734-755. [CrossRef]

43. Jorge, P.; Bezin, Y.; Grossoni, I.; Neves, S. Modelling Track Flexibility in Turnouts Using MBS Approach. In Lecture Notes in Mechanical Engineering, Proceedings of the Advances in Dynamics of Vehicles on Roads and Tracks (IAVSD 2019), Gothenburg, Sweden, 12-16 August 2019; Klomp, M., Bruzelius, F., Nielsen, J., Hillemyr, A., Eds.; Springer International Publishing: Cham, Switzerland, 2020; pp. 359-366.

44. Lu, C.; Rodríguez-Arana, B.; Prada, J.G.; Meléndez, J.; Martínez-Esnaola, J.M. A Full explicit finite element simulation for the study of interaction between wheelset and switch panel. Veh. Syst. Dyn. 2020, 58, 229-248. [CrossRef]

45. Pletz, M.; Daves, W.; Ossberger, H. A wheel set/crossing model regarding impact, sliding and deformation-Explicit finite element approach. Wear 2012, 294-295, 446-456. [CrossRef]

46. Gao, Y.; Wang, P.; Liu, Y.; Xu, J.; Dong, Z.; Wang, K. Investigation on wheel-rail contact and damage behavior in a flange bearing frog with explicit finite element method. Math. Probl. Eng. 2019, 2019. [CrossRef]

47. Pletz, M.; Daves, W.; Yao, W.; Ossberger, H. Rolling contact fatigue of three crossing nose materials-Multiscale FE approach. Wear 2014, 314, 69-77. [CrossRef]

48. Wiedorn, J.; Daves, W.; Ossberger, U.; Ossberger, H.; Pletz, M. Numerical assessment of materials used in railway crossings by predicting damage initiation-Validation and application. Wear 2018, 414-415, 136-150. [CrossRef]

49. Skrypnyk, R.; Nielsen, J.C.O.; Ekh, M.; Pålsson, B.A. Metamodelling of wheel-rail normal contact in railway crossings with elasto-plastic material behaviour. Eng. Comput. 2019, 35, 139-155. [CrossRef]

50. El-sayed, H.M.; Lotfy, M.; El-din Zohny, H.N.; Riad, H.S. Prediction of fatigue crack initiation life in railheads using finite element analysis. Ain Shams Eng. J. 2018, 9, 2329-2342. [CrossRef]

51. Xin, L.; Markine, V.; Shevtsov, I. Analysis of the effect of repair welding/grinding on the performance of railway crossings using field measurements and finite element modeling. Proc. Inst. Mech. Eng. Part F J. Rail Rapid Transit 2018, 232, 798-815. [CrossRef]

52. Ma, Y.; Markine, V.L.; Mashal, A.A. Rail surface crack initiation analysis using multi-scale coupling approach. In Proceedings of the Dynamics of Vehicles on Roads and Tracks-Proceedings of the 24th Symposium of the International Association for Vehicle System Dynamics (IAVSD 2015), Graz, Austria, 17-21 August 2015; pp. 1611-1622.

53. Wei, W.; Yuan, C.; Wu, R.; Chen, F.; Jiao, W. Wear of a crossing under dynamic wheel impact. Wear 2019, 436-437, 202997. [CrossRef]

54. Wiest, M.; Daves, W.; Fischer, F.D.; Ossberger, H. Deformation and damage of a crossing nose due to wheel passages. Wear 2008, 265, 1431-1438. [CrossRef]

55. Gao, Y.; Xu, J.; Wang, P.; Dong, Z.; Liu, Y.; Wang, K. Numerical study of the transition characteristics and related degradation at the flange bearing frog. Proc. Inst. Mech. Eng. Part F J. Rail Rapid Transit 2020. [CrossRef]

56. Pletz, M.; Daves, W.; Ossberger, H. A wheel passing a crossing nose: Dynamic analysis under high axle loads using finite element modelling. Proc. Inst. Mech. Eng. Part F J. Rail Rapid Transit 2012, 226, 603-611. [CrossRef]

57. Xiao, J.; Zhang, F.; Qian, L. Numerical simulation of stress and deformation in a railway crossing. Eng. Fail. Anal. 2011, 18, 2296-2304. [CrossRef]

58. Wiedorn, J.; Daves, W.; Ossberger, U.; Ossberger, H.; Pletz, M. Simplified explicit finite element model for the impact of a wheel on a crossing-Validation and parameter study. Tribol. Int. 2017, 111, 254-264. [CrossRef]

59. Ma, Y.; Mashal, A.A.; Markine, V.L. Modelling and experimental validation of dynamic impact in 1:9 railway crossing panel. Tribol. Int. 2018, 118, 208-226. [CrossRef]

60. Guo, S.L.; Sun, D.Y.; Zhang, F.C.; Feng, X.Y.; Qian, L.H. Damage of a Hadfield steel crossing due to wheel rolling impact passages. Wear 2013, 305, 267-273. [CrossRef]

61. Kovalchuk, V.; Bolzhelarskyi, Y.; Parneta, B.; Pentsak, A.; Petrenko, O.; Mudryy, I. Evaluation of the stressed-strained state of crossings of the 1/11 type turnouts by the finite element method. East. Eur. J. Enterp. Technol. 2017, 4, 10-16. [CrossRef]

62. Li, Z.; Zhao, X.; Dollevoet, R.; Molodova, M. Differential wear and plastic deformation as causes of squat at track local stiffness change combined with other track short defects. Veh. Syst. Dyn. 2008, 46, 237-246. [CrossRef]

63. Xin, L.; Markine, V.L.; Shevtsov, I.Y. Analysis approach of turnout crossing performance by field measurements and finite element modeling. In Proceedings of the Dynamics of Vehicles on Roads and Tracks-Proceedings of the 24th Symposium of the International Association for Vehicle System Dynamics (IAVSD 2015), Graz, Austria, 17-21 August 2015; pp. 1593-1600. 
64. Xin, L.; Markine, V.L.; Shevtsov, I.Y. Numerical analysis of the dynamic interaction between wheel set and turnout crossing using the explicit finite element method. Veh. Syst. Dyn. 2016, 54, 301-327. [CrossRef]

65. Wei, Z.; Núñez, A.; Liu, X.; Dollevoet, R.; Li, Z. Multi-criteria evaluation of wheel/rail degradation at railway crossings. Tribol. Int. 2020, 144. [CrossRef]

66. Wei, Z.; Núñez, A.; Boogaard, A.; Dollevoet, R.; Li, Z. Method for evaluating the performance of railway crossing rails after long-term service. Tribol. Int. 2018, 123, 337-348. [CrossRef]

67. Wei, Z.; Shen, C.; Li, Z.; Dollevoet, R. Wheel-Rail Impact at Crossings: Relating Dynamic Frictional Contact to Degradation. J. Comput. Nonlinear Dyn. 2017, 12. [CrossRef]

68. Shih, J.Y.; Hemida, H.; Stewart, E.; Roberts, C. Understanding the impact of train run-throughs on railway switches using finite element analysis. Proc. Inst. Mech. Eng. Part F J. Rail Rapid Transit 2019, 233, 359-369. [CrossRef]

69. Sae Siew, J.; Mirza, O.; Kaewunruen, S. Nonlinear Finite Element Modelling of Railway Turnout System considering Bearer/Sleeper-Ballast Interaction. J. Struct. 2015, 2015, 1-11. [CrossRef]

70. Salajka, V.; Smolka, M.; Kala, J.; Plášek, O. Dynamical response of railway switches and crossings. MATEC Web Conf. 2017, 107, 1-6. [CrossRef]

71. Smith, M. ABAQUS/Standard User's Manual, Version 6.9; Dassault Systèmes Simulia Corp.: Providence, RI, USA, 2009.

72. Bezin, Y. An Integrated Flexible Track System Model for Railway Vehicle Dynamics. Ph.D. Thesis, Manchester Metropolitan University, Manchester, UK, 2008.

73. Simulia, A.G. SIMPACK User's Manual 2019; Dassault Systèmes Simulia Corp.: Johnston, RI, USA, 2019.

74. Kassa, E.; Johansson, G. Simulation of train-turnout interaction and plastic deformation of rail profiles. Veh. Syst. Dyn. 2006, 44, 349-359. [CrossRef]

75. Skrypnyk, R.; Ossberger, U.; Pålsson, B.A.; Ekh, M.; Nielsen, J.C.O. Long-term rail profile damage in a railway crossing: Field measurements and numerical simulations. Wear 2021, 472-473, 1-13. [CrossRef]

76. Skrypnyk, R.; Pålsson, B.A.; Nielsen, J.C.O.; Ekh, M. On the influence of crossing angle on long-term rail damage evolution in railway crossings. Int. J. Rail Transp. 2021,1-17. [CrossRef]

77. Li, X.; Nielsen, J.C.O.; Pålsson, B.A. Simulation of track settlement in railway turnouts. Veh. Syst. Dyn. 2014, 52, 421-439. [CrossRef]

78. Zhu, J.Y.; Thompson, D.J. Characterization of forces, dynamic response, and sound radiation from an articulated switch sleeper in a turnout system. Proc. Inst. Mech. Eng. Part F J. Rail Rapid Transit 2010, 224, 53-60. [CrossRef]

79. Markine, V.L.; Steenbergen, M.J.M.M.; Shevtsov, I.Y. Combatting RCF on switch points by tuning elastic track properties. Wear 2011, 271, 158-167. [CrossRef]

80. Grossoni, I.; Bezin, Y.; Neves, S. Optimisation of support stiffness at railway crossings. Veh. Syst. Dyn. 2018, 56, 1072-1096. [CrossRef]

81. Grossoni, I.; Le Pen, L.M.; Jorge, P.; Bezin, Y.; Watson, G.V.R.; Kostovasilis, D.; Powrie, W. The role of stiffness variation in switches and crossings: Comparison of vehicle-track interaction models with field measurements. Proc. Inst. Mech. Eng. Part F J. Rail Rapid Transit 2019, 1-14. [CrossRef]

82. Hamarat, M.; Papaelias, M.; Silvast, M.; Kaewunruen, S. The effect of unsupported sleepers/bearers on dynamic phenomena of a railway turnout system under impact loads. Appl. Sci. 2020, 10, 2320. [CrossRef]

83. Grossoni, I.; Powrie, W.; Zervos, A.; Bezin, Y.; Le Pen, L. Modelling railway ballasted track settlement in vehicle-track interaction analysis. Transp. Geotech. 2021, 26, 100433. [CrossRef]

84. Ren, Z.; Sun, S.; Zhai, W. Study on lateral dynamic characteristics of vehicle/turnout system. Veh. Syst. Dyn. 2005, 43, 285-303. [CrossRef]

85. Hamarat, M.; Kaewunruen, S.; Papaelias, M.; Silvast, M. New insights from multibody dynamic analyses of a turnout system under impact loads. Appl. Sci. 2019, 9, 4080. [CrossRef]

86. Xu, J.; Wang, P.; Ma, X.; Gao, Y.; Chen, R. Stiffness characteristics of high-speed railway turnout and the effect on the dynamic train-Turnout interaction. Shock Vib. 2016, 2016. [CrossRef]

87. Wan, C.; Markine, V.L.; Shevtsov, I.Y. Analysis of train/turnout vertical interaction using a fast numerical model and validation of that model. Proc. Inst. Mech. Eng. Part F J. Rail Rapid Transit 2014, 228, 730-743. [CrossRef]

88. Kassa, E.; Cai, X. Modelling of the Dynamic Train-Track-Substructure Interaction for Track Monitoring; Springer International Publishing: Cham, Switzerland, 2021; ISBN 9783030624729.

89. Wiest, M.; Kassa, E.; Daves, W.; Nielsen, J.C.O.; Ossberger, H. Assessment of methods for calculating contact pressure in wheel-rail/switch contact. Wear 2008, 265, 1439-1445. [CrossRef]

90. Andersson, C.; Dahlberg, T. Wheel/rail impacts at a railway turnout crossing. Proc. Inst. Mech. Eng. Part F J. Rail Rapid Transit 1998, 212, 123-134. [CrossRef]

91. Xu, J.; Wang, J.; Wang, P.; Chen, J.; Gao, Y.; Chen, R.; Xie, K. Study on the derailment behaviour of a railway wheelset with solid axles in a railway turnout. Veh. Syst. Dyn. 2020, 58, 123-143. [CrossRef]

92. Fang, J.; Chen, R.; Hu, C.; Chen, J.; Xu, J.; Wang, P. Simulation analysis of high-speed turnout point rail switching force considering influence of external locking device. Proc. Inst. Mech. Eng. Part F J. Rail Rapid Transit 2021. [CrossRef]

93. Li, X.; Torstensson, P.T.; Nielsen, J.C.O. Simulation of vertical dynamic vehicle-track interaction in a railway crossing using Green's functions. J. Sound Vib. 2017, 410, 318-329. [CrossRef] 
94. Chen, R.; Chen, J.; Wang, P.; Fang, J.; Xu, J. Impact of wheel profile evolution on wheel-rail dynamic interaction and surface initiated rolling contact fatigue in turnouts. Wear 2019, 438-439, 203109. [CrossRef]

95. Qian, Y.; Wang, P.; Chen, J.; Bethel Lulu, G.; Xu, J.; An, B. Numerical investigation of the influence of the creep curve on the wheel-rail contact damage in high-speed railway turnouts. Proc. Inst. Mech. Eng. Part F J. Rail Rapid Transit 2018, 233, 926-936. [CrossRef]

96. Shu, X.; Wilson, N.; Sasaoka, C.; Elkins, J. Development of a real-time wheel/rail contact model in NUCARS ${ }^{\circledR} 1$ and application to diamond crossing and turnout design simulations. Veh. Syst. Dyn. 2006, 44, 251-260. [CrossRef]

97. Alfi, S.; Bruni, S. Mathematical modelling of train-turnout interaction. Veh. Syst. Dyn. 2009, 3114, 551-574. [CrossRef]

98. Li, X.; Nielsen, J.C.O.; Torstensson, P.T. Simulation of wheel-rail impact load and sleeper-ballast contact pressure in railway crossings using a Green's function approach. J. Sound Vib. 2019, 463. [CrossRef]

99. Torstensson, P.T.; Squicciarini, G.; Krüger, M.; Pålsson, B.A.; Nielsen, J.C.O.; Thompson, D.J. Wheel-rail impact loads and noise generated at railway crossings-Influence of vehicle speed and crossing dip angle. J. Sound Vib. 2019, 456, 119-136. [CrossRef]

100. Lai, J.; Xu, J.; Wang, P.; Yan, Z.; Wang, S.; Chen, R.; Sun, J. Numerical investigation of dynamic derailment behavior of railway vehicle when passing through a turnout. Eng. Fail. Anal. 2021, 121, 105132. [CrossRef]

101. Xu, J.; Ma, Q.; Zhao, S.; Chen, J.; Qian, Y.; Chen, R.; Wang, P. Effect of wheel flat on dynamic wheel-rail impact in railway turnouts. Veh. Syst. Dyn. 2021. [CrossRef]

102. Hertz, H. Über die Berührung fester elastischer Körper. J. Die Reine Angew. Math. 1881, 319, $156-171$.

103. Piotrowski, J.; Kik, W. A simplified model of wheel/rail contact mechanics for non-Hertzian problems and its application in rail vehicle dynamic simulations. Veh. Syst. Dyn. 2008, 46, 27-48. [CrossRef]

104. Ayasse, J.B.; Chollet, H. Determination of the wheel rail contact patch in semi-Hertzian conditions. Veh. Syst. Dyn. 2005, 43, 161-172. [CrossRef]

105. Sichani, M.S.; Enblom, R.; Berg, M. A novel method to model wheel-rail normal contact in vehicle dynamics simulation. Veh. Syst. Dyn. 2014, 52, 1752-1764. [CrossRef]

106. Kalker, J.J. Wheel-rail rolling contact theory. Wear 1991, 144, 243-261. [CrossRef]

107. Sebès, M.; Chevalier, L.; Ayasse, J.B.; Chollet, H. A fast-simplified wheel-rail contact model consistent with perfect plastic materials. Veh. Syst. Dyn. 2012, 50, 1453-1471. [CrossRef]

108. Zhao, X.; Li, Z. The solution of frictional wheel-rail rolling contact with a 3D transient finite element model: Validation and error analysis. Wear 2011, 271, 444-452. [CrossRef]

109. Iwnicki, S. Handbook of Railway Vehicle Dynamics, 1st ed.; CRC Press: Boca Raton, FL, USA, 2006; ISBN 9781420004892.

110. Sh. Sichani, M.; Enblom, R.; Berg, M. An alternative to FASTSIM for tangential solution of the wheel-rail contact. Veh. Syst. Dyn. 2016, 54, 748-764. [CrossRef]

111. Shen, Z.Y.; Hedrick, J.K.; Elkins, J.A. Comparison of Alternative Creep Force Models for Rail Vehicle Dynamic Analysis. Veh. Syst. Dyn. 1984, 12, 591-605. [CrossRef]

112. Vermeulen, P.J.; Johnson, K.L. Contact of nonspherical elastic bodies transmitting tangential forces. J. Appl. Mech. Trans. ASME 1964, 31, 338-340. [CrossRef]

113. Sebès, M.; Chollet, H.; Ayasse, J.B.; Chevalier, L. A multi-Hertzian contact model considering plasticity. Wear 2014, 314, 118-124. [CrossRef]

114. Burstow, M. Whole Life Rail Model Application and Development: Development of a Rolling Contact Fatigue Damage Parameter (Burstow Report); Rail Safety Standards Board (RSSB): London, UK, 2003.

115. Evans, J.R.; Burstow, M.C. Vehicle/track interaction and rolling contact fatigue in rails in the UK. Veh. Syst. Dyn. 2007, 3114, 708-717. [CrossRef]

116. Evans, J.R.; Lee, T.K.Y.; Hon, C.C. Optimising the wheel/rail interface on a modern urban rail system. Veh. Syst. Dyn. 2008, 46, 119-127. [CrossRef]

117. Harvey, R.F.; McEwen, I.J. The Relationship between Wear Number and Wheel/Rail Wear in the Laboratory and the Field; British Rail Research Report TM-VDY-001; Rail Safety Standards Board (RSSB): London, UK, 1986.

118. Archard, J.F. Contact and rubbing of flat surfaces. J. Appl. Phys. 1953, 24, 981-988. [CrossRef]

119. Peng, B.; Iwnicki, S.; Shackleton, P.; Crosbee, D. Comparison of wear models for simulation of railway wheel polygonization. Wear 2019, 436-437, 203010. [CrossRef]

120. Meghoe, A.; Loendersloot, R.; Tinga, T. Rail wear and remaining life prediction using meta-models. Int. J. Rail Transp. 2020, 8 , 1-26. [CrossRef]

121. Jiang, Y.; Sehitoglu, H. A model for rolling contact failure. Wear 1999, 224, 38-49. [CrossRef]

122. Johnson, K.L. The Strength of Surfaces in Rolling Contact. Proc. Inst. Mech. Eng. Part C Mech. Eng. Sci. 1989, 203, 151-163. [CrossRef]

123. Sun, Y.Q.; Spiryagin, M.; Cole, C.; Nielsen, D. Wheel-rail wear investigation on a heavy haul balloon loop track through simulations of slow speed wagon dynamics. Transport 2018, 33, 843-852. [CrossRef]

124. Dang Van, K.; Maitournam, M.H.; Moumni, Z.; Roger, F. A comprehensive approach for modeling fatigue and fracture of rails. Eng. Fract. Mech. 2009, 76, 2626-2636. [CrossRef]

125. Ohno, N.; Wang, J.D. Kinematic hardening rules with critical state of dynamic recovery, part I: Formulation and basic features for ratchetting behavior. Int. J. Plast. 1993, 9, 375-390. [CrossRef] 
126. Lemaitre, J.; Chaboche, J.-L. Mechanics of Solid Materials; Cambridge University Press: Cambridge, UK, 1990 ; ISBN 9780521328531.

127. Johansson, G.; Ahlström, J.; Ekh, M. Parameter identification and modeling of large ratcheting strains in carbon steel. Comput. Struct. 2006, 84, 1002-1011. [CrossRef]

128. Shih, J.Y.; Kostovasilis, D.; Bezin, Y.; Thompson, D.J. Modelling options for ballast track dynamics. In Proceedings of the 24th International Congress on Sound and Vibration (ICSV 2017), London, UK, 23-27 July 2017; pp. 1-15.

129. Cornish, A.; Smith, R.A.; Dear, J. Monitoring of strain of in-service railway switch rails through field experimentation. Proc. Inst. Mech. Eng. Part F J. Rail Rapid Transit 2016, 230, 1429-1439. [CrossRef]

130. Kassa, E.; Nielsen, J.C.O. Dynamic interaction between train and railway turnout: Full-scale field test and validation of simulation models. Veh. Syst. Dyn. 2008, 46, 521-534. [CrossRef]

131. Babyak, M.; Keršys, R.; Neduzha, L. Improving the Dependability Evaluation Technique of a Transport Vehicle. In Proceedings of the 24th International Scientific Conference-Transport Means 2020, Palanga, Lithuania, 30 September-2 October 2020 ; pp. 646-651. 